\title{
The seasonally-varying influence of ENSO on rainfall and tropical cyclone activity in the Philippines
}

\author{
Bradfield Lyon · Suzana J. Camargo
}

Received: 23 October 2007 / Accepted: 13 February 2008/Published online: 26 February 2008

(C) Springer-Verlag 2008

\begin{abstract}
An observational study covering the period 1950-2002 examines a seasonal reversal in the ENSO rainfall signal in the north-central Philippines. In boreal Summer of El Niño (La Niña) events, above (below) average rainfall typically occurs in this area. Rainfall anomalies of opposite sign develop across the country in the subsequent fall. This study investigates the seasonal evolution of the anomalous atmospheric circulation over the western North Pacific (WNP) during both El Niño and La Niña and places these features in the context of the large-scale evolution of ENSO events, including an analysis of changes in tropical cyclone activity affecting the Philippines. The results show that during boreal summer of El Niño (La Niña) events, a relatively narrow, zonally elongated band of enhanced (reduced) low-level westerlies develops across the WNP which serves to increase (decrease) the summer monsoon flow and moisture flux over the north-central Philippines and is associated with an increase (decrease) in the strength of the WNP monsoon trough via the anomalous relative vorticity. Tropical cyclone activity is shown to be enhanced (reduced) in the study region during boreal summer of El Niño (La Niña) events, which is related to the increase (decrease) of mid-level atmospheric moisture, as diagnosed using a genesis potential index. The subsequent evolution shows development of an anomalous anticyclone (cyclone)
\end{abstract}

\footnotetext{
B. Lyon $(\varangle) \cdot$ S. J. Camargo

International Research Institute for Climate and Society,

The Earth Institute at Columbia University,

Palisades, NY 10964, USA

e-mail: blyon@iri.columbia.edu

Present Address:

S. J. Camargo

Lamont-Doherty Earth Observatory of Columbia University,

Palisades, NY 10964, USA
}

over the WNP in El Niño (La Niña) and the well-known tendency for below (above) average rainfall in the fall. Prolonged ENSO events also exhibit seasonal rainfall sign reversals in the Philippines with a similar evolution in atmospheric circulation.

Keywords Philippines - ENSO - Typhoons - Rainfall · Seasonality

\section{Introduction}

In regions of the globe affected by the El Niño-Southern Oscillation (ENSO) the season (or seasons) of largest response varies substantially due in large part to the life cycle of El Niño (EN) or La Niña (LN) events relative to the annual cycle of regional climate. In this paper an observational study of the seasonally varying response to ENSO in the Philippines is presented which covers the period 1950-2002. While several studies have examined the influence of ENSO on the seasonal and regional climate of Southeast Asia, the local consequences for the Philippines have received little attention and have not been documented in detail.

Of particular interest to the current study is the identification of recurrent, anomalous features of the regional and large scale climate system associated with a recently documented reversal in the ENSO rainfall signal in the Philippines between boreal summer and the subsequent fall (Lyon et al. 2006). That study used over 50 years of monthly rainfall data from 40 synoptic stations across the country and found that during EN (LN) summer season rainfall has a statistically significant occurrence of being above (below) the long-term median in the north-central Philippines before drier (wetter) than average conditions 
settle in across most of the country by fall. The JulyAugust-September season (JAS; all other seasons hereafter abbreviated using similar notation) was identified as having the strongest signal that subsequently reversed by OND. Observational studies dating back to the work of Walker and Bliss (1932) and later Kiladis and Diaz (1989) and Kripalani and Kulkarni (1998), among others, have provided hints that such a seasonal reversal may occur in the Philippines, although the number of stations utilized in these studies was limited.

The seasonal reversal of the ENSO signal in Southeast Asia is an intriguing aspect of regional climate variability that previous research has not fully explored. This study extends previous investigations of the influence of ENSO in the region in three fundamental ways. First, the primary focus of the study is on variations in rainfall in the Philippines where few detailed studies exist in the published literature. When placed in a regional context, it is not clear why the ENSO rainfall signal in JAS should be confined to a relatively narrow band of the north-central region of the Philippines. The ENSO rainfall signal in Indonesia, for example, shows generally opposite behavior, with greater spatial coherence in the rainfall signal during JAS, but not in OND (Hendon 2003); besides there is no reversal in sign between these seasons. Secondly, we consider the influence of ENSO on environmental factors which are directly associated with the behavior of tropical cyclones (TCs) affecting the Philippines which has not been analyzed previously. Finally, as will be shown, the seasonal reversal in the rainfall signal in the Philippines occurs in consecutive years of prolonged ENSO events. How these long-lived ENSO events affect the seasonally varying regional atmospheric circulation has not been examined in detail previously.

Previous studies which examined the influence of ENSO on the seasonal monsoon systems of East and Southeast Asia are summarized in Chang (2004). Prior work has shown that in the boreal fall of EN (LN) events an anomalous anticyclone (cyclone) typically develops in the vicinity of the Philippines (e.g., Wang et al. 2000; Juneng and Tangang 2005). Consistent with these circulation features, precipitation in most regions of the Philippines is typically below (above) average in the fall and winter of EN (LN) events (Ropelewski and Halpert 1987; Kiladis and Diaz 1989). The temporal evolution of these anomalous circulation features, with emphasis on the development of the western North Pacific (WNP) anticyclone during EN, is described in the recent observationallybased studies of Zhang et al. (1996), Wang et al. (2000), Wang and Zhang (2002), Juneng and Tangang (2005), as well as in the modeling papers by Lau and Nath (2003, 2006) and Wu et al. (2003). Previous work has also shown that during the onset phase of EN in boreal summer an anomalous cyclonic circulation is often located in the vicinity of the Philippine Sea. This circulation feature is subsequently replaced by an anomalous anticyclone during the fall (Wang et al. 2000; Wang and Zhang 2002; Wu et al. 2003; Lau et al. 2004; among others). Indeed, time series of composite monthly anomalies in the Western North Pacific summer Monsoon Index ${ }^{1}$ (WNPMI, Wang and Fan 1999; Wang et al. 2001) for both EN and LN reveal sign reversals between JAS and OND, simultaneous with the rainfall signal reversal in the Philippines (Lyon et al. 2006). The seasonal reversal of these anomalous, regional circulation features therefore appears to be closely tied to the seasonal reversal of the ENSO rainfall signal in the Philippines.

The influence of ENSO on tropical storm activity in the WNP has been widely investigated in its own right. During EN (LN) years, TCs tend to develop further to the southeast (northwest) of their climatological mean genesis locations (e.g., Chan 1985; Chen et al. 1998; Wang and Chan 2002; Chia and Ropelewski 2002). This shift in genesis location with ENSO leads to different track types in EN and LN years (Camargo et al. 2007b), with a tendency for more long lived and intense typhoons occurring in EN years, and fewer and short-living TCs in LN years (Camargo and Sobel 2005). Studies have shown statistically significant differences in landfall rates in the northern Philippines between EN and LN events with more, intense typhoons making landfall in northern Luzon in LN years (Saunders et al. 2000; Elsner and Liu 2003). In the current study a methodological approach similar to that adopted by Camargo et al. (2007a) is employed to investigate which environmental factors are most closely related to changes in the genesis of TCs in the region. Again, documenting changes in these factors in the context of the seasonal reversal in the ENSO rainfall signal in the Philippines will be emphasized.

The study is outlined as follows. The data utilized and the methodological approaches taken are described in Sect. 2. Section 3 presents an analysis of the evolution of the anomalous regional scale atmospheric circulation anomalies during EN and LN events. In Sect. 4 changes in TC activity between the boreal summer and fall, for both extreme phases of ENSO, are presented. The atmospheric response to ENSO events in the WNP is placed in a broader spatial context in Sect. 5 which also includes an examination of prolonged ENSO events. An overall summary of the study and its main conclusions are provided in Sect. 6.

\footnotetext{
1 The WNPMI is defined as the difference in the averages of the $850 \mathrm{hPa}$ zonal wind, $\left(5^{\circ} \mathrm{N}-15^{\circ} \mathrm{N}, 90^{\circ} \mathrm{E}-130^{\circ} \mathrm{E}\right)$ minus $\left(25^{\circ} \mathrm{N}-30^{\circ} \mathrm{N}\right.$, $\left.110^{\circ} \mathrm{E}-140^{\circ} \mathrm{E}\right)$.
} 


\section{Data and methodology}

\subsection{Data}

The atmospheric fields used in the study were all from the gridded analyses $\left(2.5^{\circ} \times 2.5^{\circ}\right.$ spatial resolution $)$ of the NCEP-NCAR reanalysis (Kistler et al. 2001) for the period 1950-2002. Merged, global analyses of monthly and pentad precipitation based on gages and satellite estimates were from the US Climate Prediction Center product (CMAP; Xie and Arkin 1996) which are on a $2.5^{\circ} \times 2.5^{\circ}$ lat./long. grid and cover the period 1979-2006. The station-based global analyses of monthly precipitation from 1950 to 2002 produced at the Climate Research Unit (CRU), University of East Anglia (New et al. 1999, 2000) were also used. These analyses are for land areas only and are gridded to a spatial resolution of $0.5^{\circ} \times 0.5^{\circ}$ lat./long. Monthly sea surface temperature (SST) data were from the extended reconstruction of global SST developed by Smith and Reynolds (2003) and are gridded to $2.0^{\circ} \times 2.0^{\circ}$ lat./long. Genesis locations and tracks of TCs were taken from the best track data set maintained by the US Navy's Joint Typhoon Warning Center (JTWC). TC data for the period 1950-2002 were used here. Only those TCs with tropical storm intensity or higher and whose center either crossed, or came within $100 \mathrm{~km}$ of the coastline of the Philippines were considered. To address issues of TC data quality, some analyses were performed on a subset of the JTWC data covering the period 1970-2002. Unless otherwise noted, monthly anomalies in all variables were computed relative to a 1971-2000 base period climatology. With the exception of the TC information, all data used in the study were obtained online via the Data Library at the International Research Institute for Climate and Society (IRI) (http://iridl.ldeo.columbia.edu/).

\subsection{Methodological approach}

In order to filter random weather fluctuations that are not necessarily associated with the ENSO signal, three month overlapping seasonal averages were used in most of the analyses presented. The primary seasons of interest cover the period JJA to OND as this fully captures the reversal in the ENSO rainfall signal in the Philippines. Individual ENSO events were identified using SST anomalies averaged over the Niño3.4 region $\left(5^{\circ} \mathrm{S}-5^{\circ} \mathrm{N}, 120^{\circ} \mathrm{W}-170^{\circ} \mathrm{W}\right.$; Barnston et al. 1997). An EN (LN) event was defined when the 5 month running average of the Niño3.4 SST index was $\geq 0.5^{\circ} \mathrm{C}\left(\leq-0.5^{\circ} \mathrm{C}\right)$ for six or more consecutive months. Furthermore, the onset ${ }^{2}$ of the ENSO event needs to have

\footnotetext{
2 The onset date of an ENSO event is defined as the first 3 month season when the Niño3.4 SST index first exceeds the threshold of $\pm 0.5^{\circ} \mathrm{C}$.
}

occurred by JAS. Eleven EN (1957, 1963, 1965, 1972, 1982, 1986, 1987, 1991, 1994, 1997, 2002) and $13 \mathrm{LN}$ (1950, 1954, 1955, 1956, 1964, 1970, 1971, 1973, 1974, 1975, 1988, 1998, 1999) events were identified by this method over the study period 1950-2002. The evolution of the anomalous atmospheric circulation and precipitation patterns associated with $\mathrm{EN}$ and $\mathrm{LN}$ are examined primarily through composites. Principal component analysis is also employed to emphasize specific points. The statistical significance of composite anomaly fields was determined through the $t$ test.

Using the JTWC best track data (the location and intensity of storm centers at 6-h intervals) the track density was computed, defined as the number of times the center of a TC was located within a given $2^{\circ} \times 2^{\circ}$ lat./long. box divided by the number of observations in the period of interest (e.g., a season). Analysis of environmental anomalies associated with ENSO phases were examined using the genesis potential (GP) index (Emanuel and Nolan 2004; Camargo et al. 2007a). The GP index was obtained empirically and is the product of four environmental variables related to TC development, which can be evaluated using reanalysis and SST data. The relative contribution of each term was assessed over the evolution of ENSO events. Further details of the GP index are provided in Sect. 4.

\section{Philippines ENSO signal reversal and the regional atmospheric circulation}

\subsection{Seasonal reversal of the ENSO rainfall signal}

As a starting point, the CRU precipitation data for JAS and OND during the ten strongest EN and LN events between 1950 and 2002 were used to identify regions with statistically significant rainfall anomalies across the Philippines. A statistically significant occurrence of above (below) average rainfall is seen during JAS under EN (LN) conditions (Fig. 1) in the north-central Philippines (Fig. 1a, c) in agreement with previous results. In OND (Fig. 1b, d) not only has the sign of the precipitation anomalies reversed from JAS but the spatial coverage of statistically significant values has increased, encompassing virtually all of the Philippines for both EN and LN events.

JAS rainfall averaged over the north-central Philippines (boxed region in Fig. 1a, land areas only) for all EN and LN events (1950-2002) is plotted in percentiles (obtained by ranking) in Fig. 2. In addition to indicating a propensity for the north-central Philippines to be unusually wet (dry) in JAS of EN (LN) years, JAS rainfall is also usually in the outer terciles of the historical distribution. This was the case in 9 out of $13(P<0.01) \mathrm{LN}$ and 8 out of 11 
Fig. 1 Regions of the Philippines with a statistically significant occurrence of above (dark shading) and below (light shading) average rainfall in a JAS and El Niño, b OND and El Niño, c JAS and La Niña, and d OND and La Niña. The relative shading within the above and below categories indicates the statistical significance level (90 or 95\%) (a) JAS EI Niño

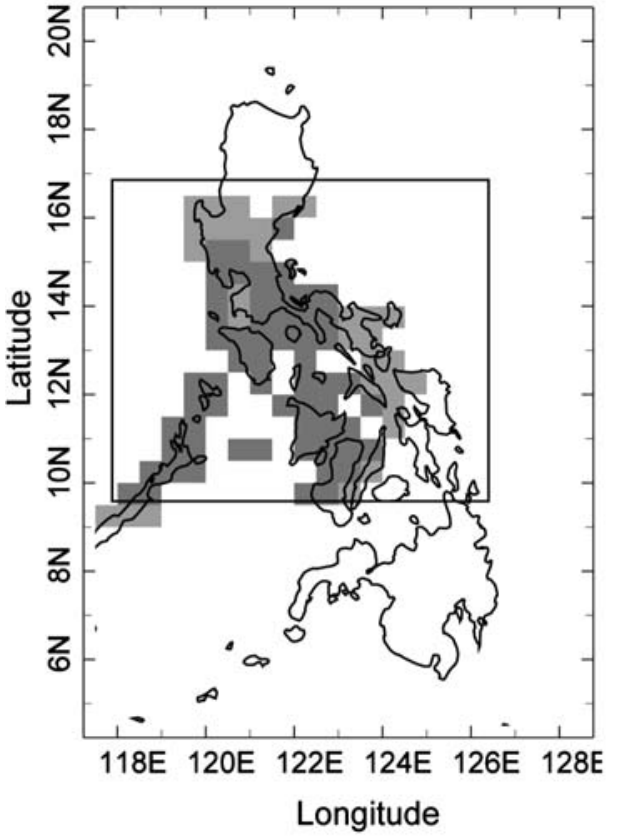

(c) JAS La Niña

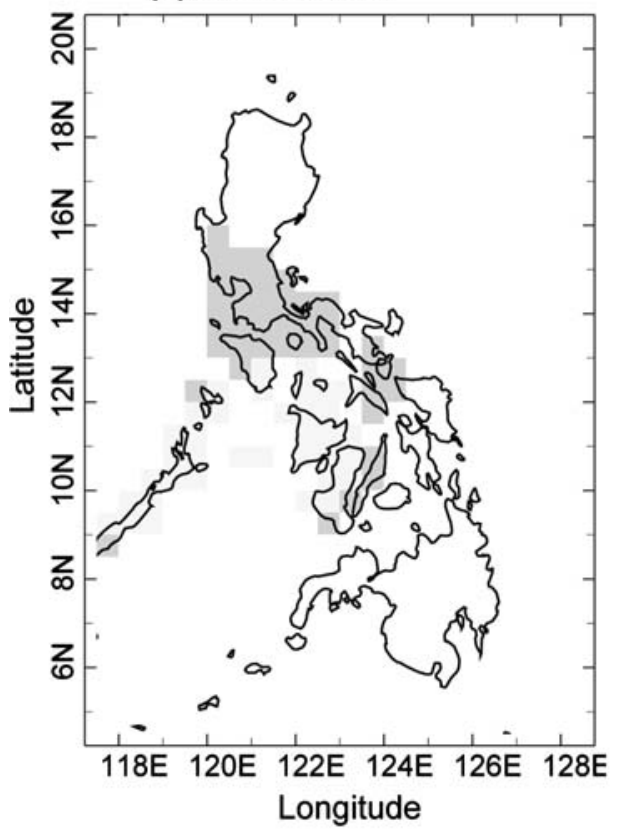

Below-Average

$95 \% \square 90 \%$
(b)OND EI Niño

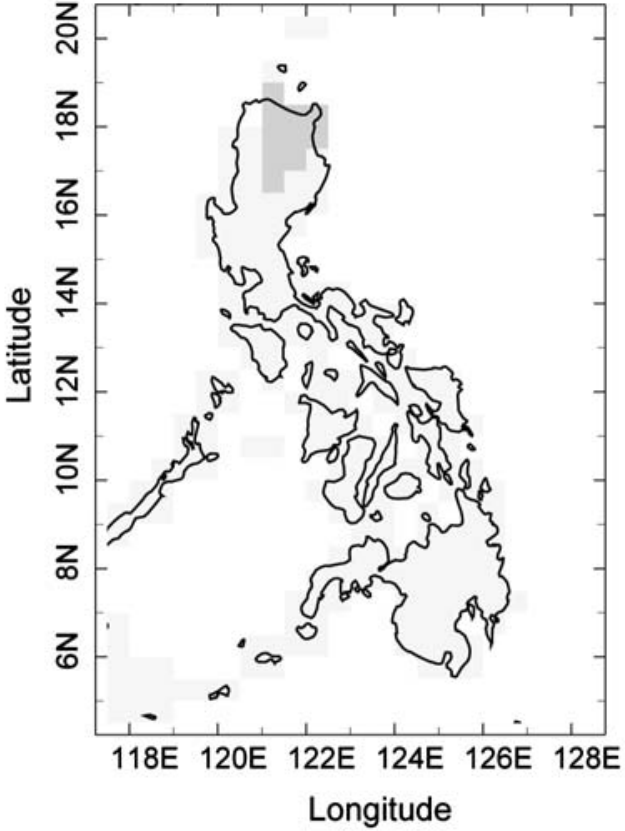

(d) OND La Niña

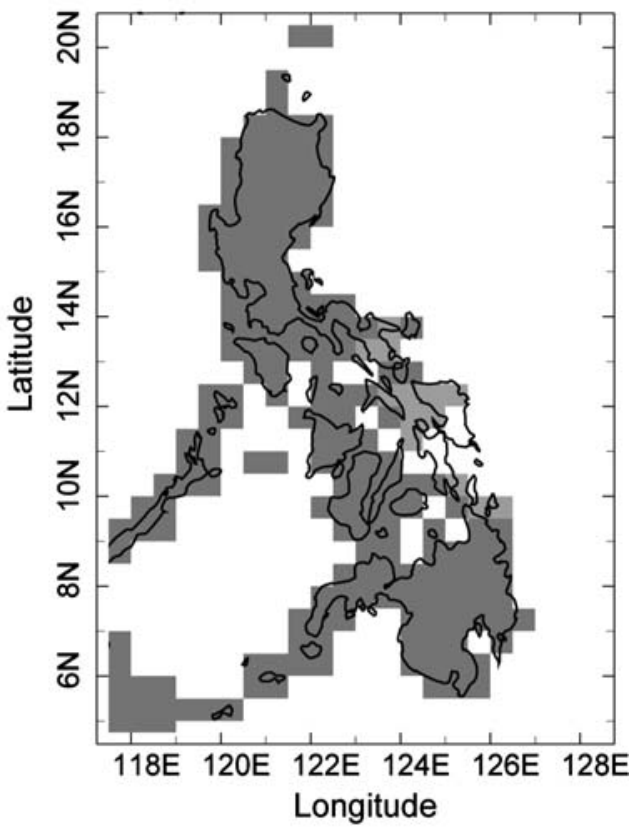

Above-Average

$90 \%$

$95 \%$
$(P<0.05)$ EN events ${ }^{3}$. Indeed, 4 of the $13(P<0.05) \mathrm{LN}$ episodes had rainfall below the 10th percentile. A given JAS season with EN or LN conditions does not necessarily follow a year of the opposite ENSO extreme phase,

\footnotetext{
3 Probabilities are based on a Fisher Exact Test as described in Lyon et al. (2006).
}

as there are examples of prolonged EN (LN) events with consecutive JAS seasons with above (below) average rainfall (Fig. 2). Thus, the seasonal reversal in the ENSO rainfall signal between JAS and OND is not simply a consequence of a transition of ENSO phase during a given calendar year. 
Fig. 2 Time series (19502002) of percentile values of rainfall averaged across the north-central Philippines (boxed region, Fig. 1a) during JAS of El Niño (white bars) and La Niña (black bars) years

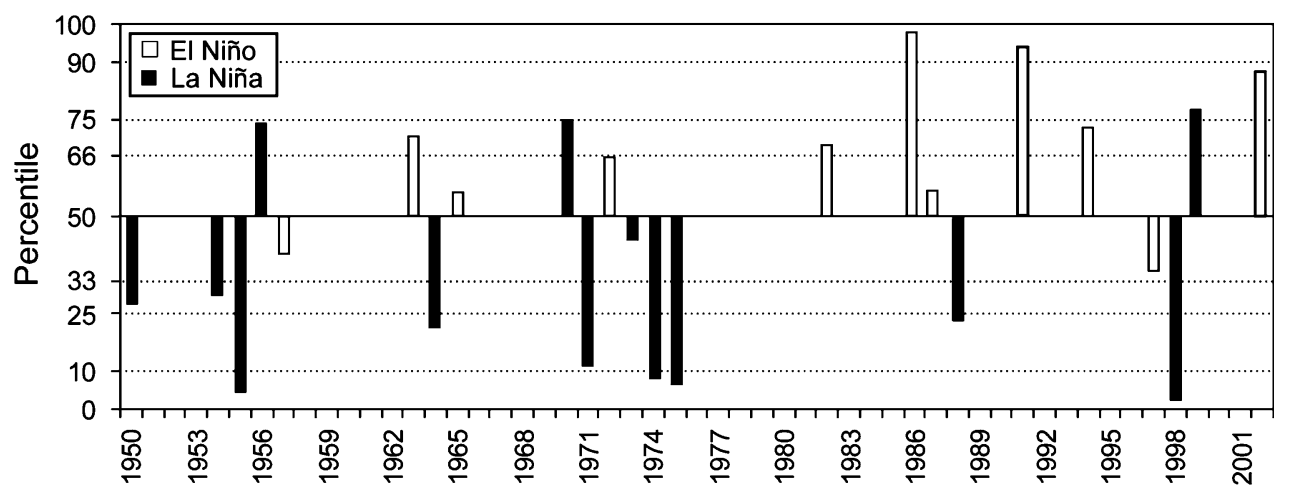

\subsection{Anomalous regional atmospheric circulation}

Composite anomalies of the $850 \mathrm{hPa}$ streamfunction and vector winds over the WNP were computed for both extreme phases of ENSO for JAS and OND (Fig. 3). Consistent with previous studies (e.g., Wu et al. 2003; Wang et al. 2003; Lau et al. 2004; Juneng and Tangang 2005), the JAS composite for EN shows an anomalous cyclonic circulation centered east of the Philippines near $15^{\circ} \mathrm{N}$ with anomalous, largely off equatorial, low-level westerlies extending from the Indochina Peninsula eastward over the Philippines. These anomalies indicate an enhancement of the summer monsoon flow over the central Philippines, favoring increased rainfall given a substantial interaction of the low-level flow with local topography in the region (e.g., Chang et al. 2005). In JAS of LN years (Fig. 3c) the pattern is generally opposite that of the EN composite with anomalous easterlies over the central and southern Philippines opposing the zonal component of the monsoon flow. The center of the now positive streamfunction anomalies east of the Philippines in JAS is, however, located westward of its negative counterpart during EN with an anomalous ridge axis extending across the northern Philippines to the South China Sea (SCS). During OND of EN (Fig. 3b) the negative streamfunction anomalies centered east of the Philippines in JAS have moved eastward with the development of an anomalous anticyclonic circulation located over the SCS (more on this in Sect. 5). The OND composite features for LN (Fig. 3d) are again generally the opposite of that for EN, with an anomalous cyclonic circulation centered west of the Philippines over the SCS.

The westward displacement of the positive streamfunction anomalies east of the Philippines during JAS of $\mathrm{LN}$ events relative to the position of the corresponding negative anomalies during EN has been related to a westward shift in the location of negative rainfall anomalies over the central equatorial Pacific during $\mathrm{LN}$ relative to the positive anomalies occurring during EN events (e.g., Lau and Nath 2006). This has been verified in climate model experiments where integrations forced only with tropical Pacific SST anomalies (climatological SSTs elsewhere) were able to generate generally similar circulation features (e.g., Lau and Nath 2000). During LN, the center of negative rainfall (and hence, diabatic heating) anomalies in the central equatorial Pacific are typically located west of the corresponding positive rainfall anomalies during EN. This behavior is related to the SST-rainfall relationship in the tropical Pacific with a westward expansion of the cold tongue during LN, dropping SST values below the convective threshold on the eastern edge of the WNP warm pool. In contrast, during EN the eastward expansion of the warm pool lifts SST values above the convective threshold on the western edge of the cold tongue (Hoerling et al. 1997). Changes in TC behavior can also affect the anomalous regional atmospheric circulation on seasonal time scales. However, that the regional anomalies described here are consistent with those from climate models that do not generate realistic TCs suggests the primary importance of forcing by anomalous tropical SSTs. As will be shown in Sect. 5, TCs account for roughly one-quarter of seasonal rainfall in the Philippines.

Therefore, the ENSO-related regional circulation (and precipitation) anomalies in the vicinity of the Philippines during JAS appear to be predominately forced by precipitation (and related SST) anomalies in the central Pacific, i.e. remote from the region. In the vicinity of Indonesia and the Philippines, SSTs in the boreal summer of developing EN (LN) events are typically below (above) average. Hendon (2003) has argued that in Indonesia local SST anomalies (as well as remote forcing) during the onset of ENSO events favor rainfall anomalies of the same sign. In the north-central Philippines, however, the ENSO rainfall signal in JAS typically has the opposite sign of the local SST anomalies, suggesting a dominant role of the regional atmospheric circulation anomalies forced by remote SSTs. Local air-sea interactions in the vicinity of the Philippines, however, are believed to become increasingly important during the boreal fall, as they influence the development (and persistence) of the anomalous anticyclone in the WNP 
(a) JAS EI Niño

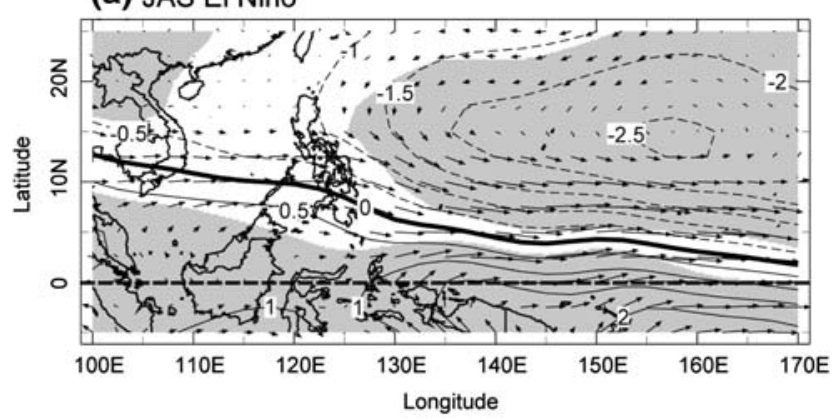

(b) OND EI Niño

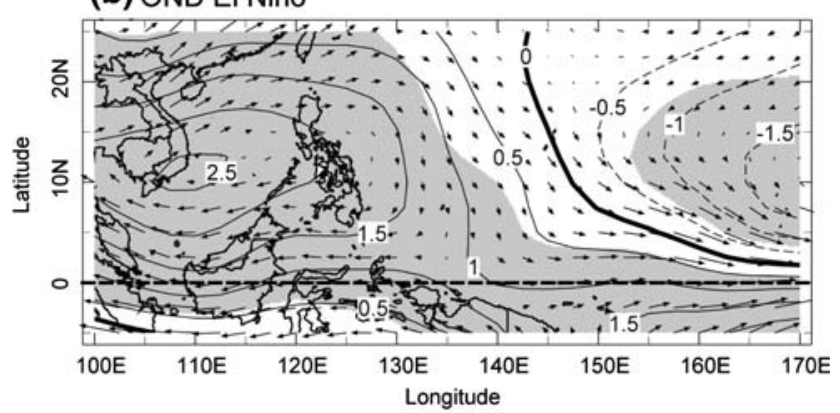

(c) JAS La Niña

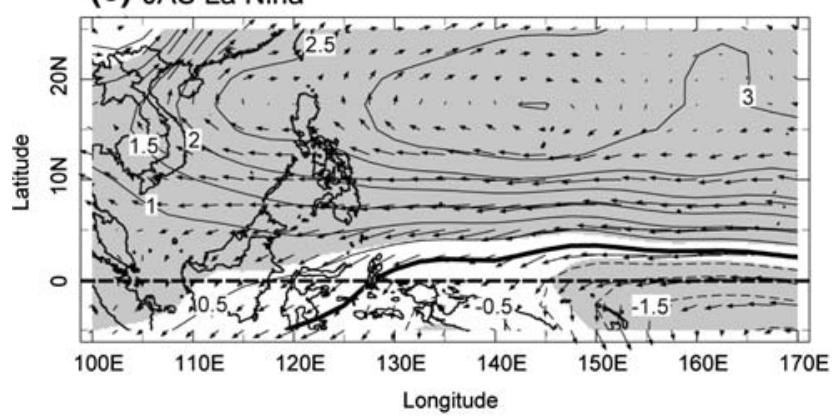

(d) OND La Niña

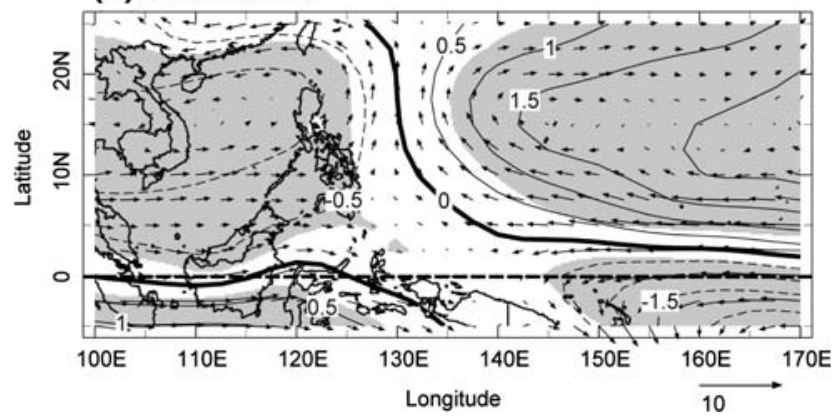

Fig. 3 Composite anomalies of the streamfunction (contours; units $\mathrm{m}^{2} \mathrm{~s}^{-1} \times 10^{-6}$ ) and vector winds at $850 \mathrm{hPa}$ for JAS and OND during El Niño and La Niña. Grey shading indicates statistical significant streamfunction anomalies at the $95 \%$ confidence level

which forms later in the ENSO cycle (e.g., Wang et al. 2000).

These regional circulation features are also related to variability of the monsoon trough, an important contributor to summer rainfall in the Philippines. Previous studies
(Lander 1994; Chan 2000; Wang and Zhang 2002; Wang and Li 2004; Lau and Nath 2006, among others) have indicated that the WNP monsoon trough tends to be enhanced and extends southeastward of its climatological mean position during the onset phase of EN events. Figure 4a shows the climatological mean location of the monsoon trough in JAS based on the relative vorticity at $850 \mathrm{hPa}$. The trough extends from the SCS eastward across the northern Philippines, then southeastward across the Philippine Sea. The change in monsoon trough intensity across the Philippines and WNP during JAS of both EN and LN is found to primarily result from changes in the zonal component of the low-level wind. That is,

$\zeta^{\prime} \approx-\frac{\partial u^{\prime}}{\partial y}$

the anomalous relative vorticity at $850 \mathrm{hPa}$ is approximately equal to the meridional gradient of the anomalous zonal wind. This can be seen by comparing Fig. $4 \mathrm{a}$ with $\mathrm{b}$ and c, the latter two showing the anomalous positive (negative) relative vorticity associated with the meridional gradient of the zonal flow during EN (LN). Thus, forcing primarily remote to the Philippines is associated with an anomalous cyclonic (anticyclonic) circulation over the WNP in JAS of $\mathrm{EN}(\mathrm{LN})$ years. A band of anomalous westerlies (easterlies) across the WNP increases (decreases) the monsoon flow across the north-central Philippines, while the horizontal shear of this flow is associated with a deepened (weakened) monsoon trough. The trough is weakened (strengthened) in the vicinity of the Philippines during OND of EN (LN) events as shown in Fig. 5 which also indicates a departure from the zonally-elongated banded structure seen in JAS as the anomalous anticyclone (cyclone) develops over the Philippines during EN (LN). These features (Figs. 3, 4) help explain why the reversal in the ENSO rainfall signal is confined to the relatively narrow region of the north-central Philippines mentioned in the Sect. 1. Also, Fig. 4 suggests that the JAS anomalous vorticity field in LN is located somewhat north of its EN counterpart. Although not seen in the UEA rainfall data (Fig. 1) this northward shift is consistent with previous results based on station rainfall data where the anomalous dry signal in JAS during LN is shifted northward of its EN counterpart (cf. Fig. 4 here with Figs. 1 and 2 in Lyon et al. 2006). In addition, Wang and Zhang (2002) suggest that the increase of wind speed across the WNP during the onset phase of EN contributes to the below average SSTs there. They suggest that this cooling, combined with thermal advection by the anomalous cyclonic circulation centered over the Philippine Sea in EN years, provide favorable preconditioning for the subsequent formation of an anomalous anticyclone in the WNP during fall, when negative SST anomalies tend to peak nearly simultaneously with the strength of the anomalous anticyclone. 
(a) JAS Climatology

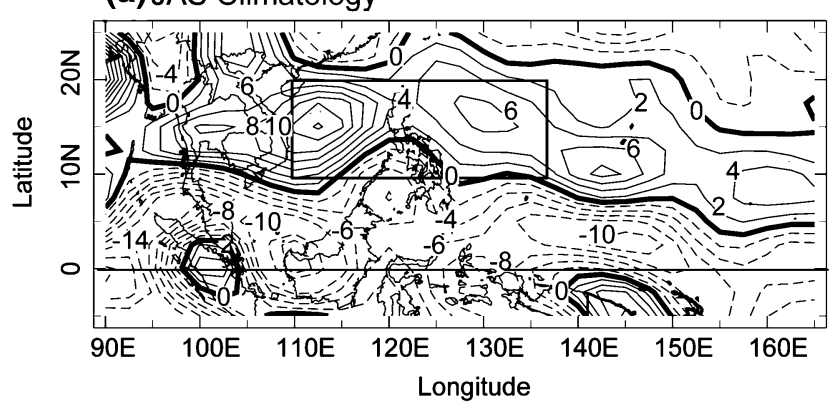

(b) JAS Anomaly EI Niño

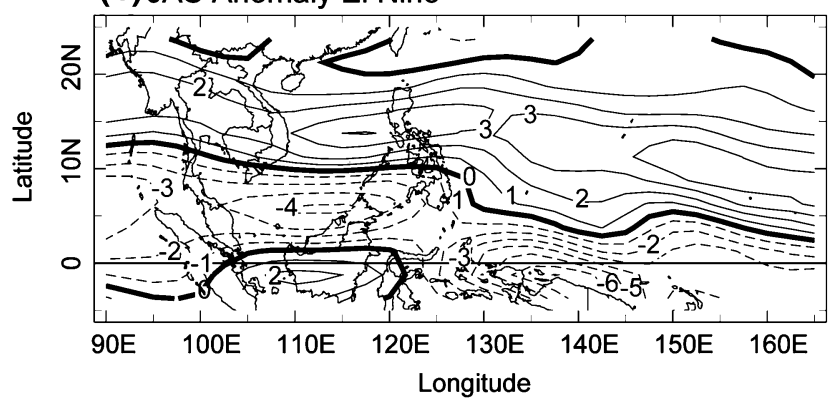

(c) JAS Anomaly La Niña

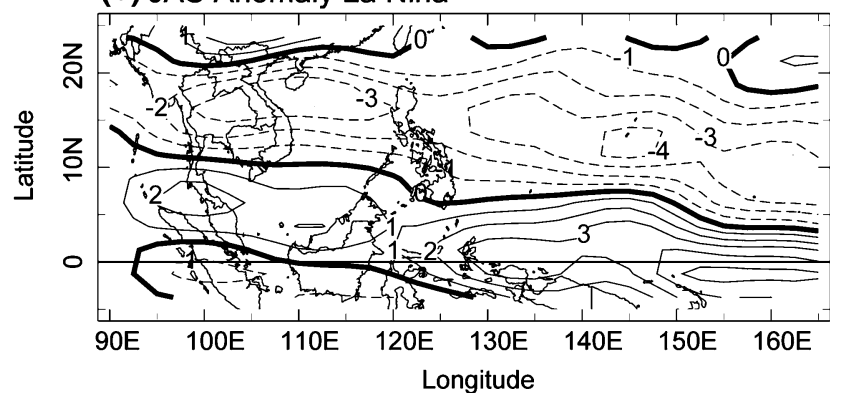

Fig. 4 Relative vorticity at $850 \mathrm{hPa}$ for JAS (contours; units $\mathrm{s}^{-}$ $1 \times 10^{6}$ ) showing (a) climatology, and anomalous voticity based on meridional shear of composite zonal wind anomalies for (b) El Niño and (c) La Niña

\subsection{Anomalous regional moisture flux}

Previous work has shown that over the north-central Philippines the total moisture flux tends to be enhanced (reduced) in JAS of EN (LN) years, a tendency which reverses sign by OND for both ENSO phases (Juneng and Tangang 2005; Lyon et al. 2006). These studies, however, did not evaluate the contributions of various processes to these fluxes, which are considered here. The horizontal wind vector $\boldsymbol{V}$, and specific humidity $q$, both at $850 \mathrm{hPa}$, were decomposed as the sum of a climatological mean and anomalous components. Doing so, the anomalous moisture flux (here averaged over different seasons of interest) may be written as the sum of three terms,

$(\mathrm{q} \boldsymbol{V})_{a}=q_{c} \boldsymbol{V}_{a}+q_{a} \boldsymbol{V}_{c}+\left(q_{a} \boldsymbol{V}_{a}\right)_{a}$

\section{(a) OND Climatology}

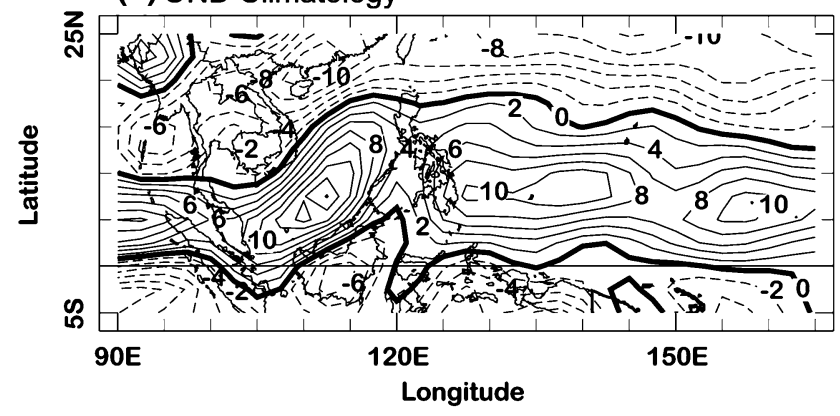

(b)OND Anomaly EI Niño

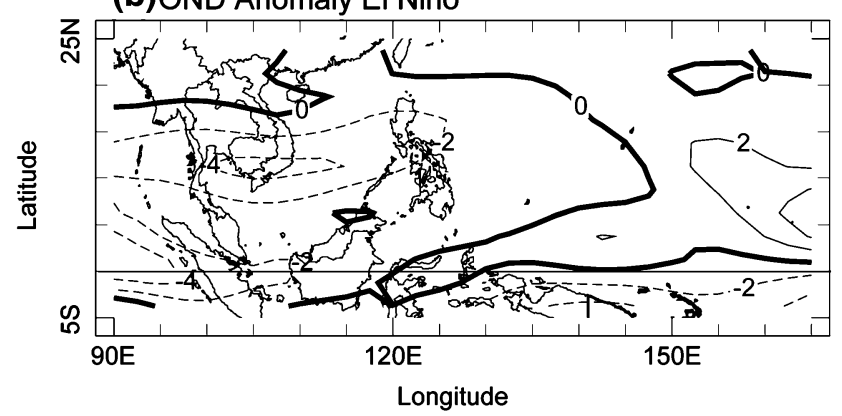

(c) OND Anomaly La Niña

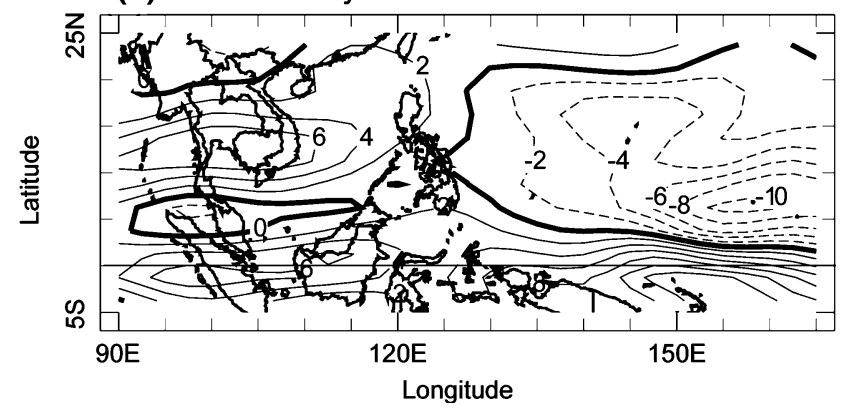

Fig. 5 As in Fig. 4 but for OND

where the subscripts $a$ and $c$ denote the anomalous and climatological values, respectively. Each of the terms in Eq. (2) was evaluated using daily data to construct seasonal composites for EN and LN events. Some caveats apply here. An examination of the specific humidity field at $850 \mathrm{hPa}$ across the tropical and subtropical WNP in the reanalysis revealed a systematic "dry" bias prior to the late 1970s. In addition, even for the late 1970s onward, comparison of reanalysis moisture fields with those derived from remote sensing products suggest that water content and precipitation is underestimated in the oceanic tropical convergence zones. There is also a tendency for too much rainfall across parts of China and Indochina, particularly during boreal summer (Annamalai et al. 1999; Trenberth and Guillemont 1998). Here, the focus is on anomalous moisture transport, not absolute values, but given the apparent bias in the first decades of the data, two base 
periods were used in computing the anomalies: 1950-1978 and 1979-2002.

The first term on the right-hand side of Eq (2), the anomalous $850 \mathrm{hPa}$ wind acting on the climatological specific humidity field, is by far the main contribution to the total anomalous flux and is shown in Fig. 6. During JAS of EN years (Fig. 6a) a band of enhanced westerly moisture flux, centered north of the equator, extends from the SCS across the central Philippines to the tropical WNP. A generally similar pattern, with vector direction reversed, is seen for the composite LN (Fig. 6c). In OND the largest anomalous flux during EN (Fig. 6b) is centered roughly along the equator, with the westerly (easterly) anomalies well east of the Philippines (western Indonesia). Relatively weak anomalies are found over the Philippines in OND where an anticyclonic circulation is indicated, consistent with the $850 \mathrm{hPa}$ wind anomalies shown in Fig. 3. The LN composite for OND (Fig. 6d) is again generally the inverse of the situation during EN, with easterly anomalies centered roughly on the equator and east of the Philippines with an anomalous cyclonic circulation over the Philippines.

The second term in Eq. (2), the contribution of anomalous specific humidity on the moisture flux by the climatological wind (Fig. 7, for JAS), has a much smaller magnitude than the first term in both JAS and OND. In JAS, it reinforces the first term across the central Philippines during both EN and LN. This result indicates that the enhanced (reduced) monsoon flow across the central Philippines in JAS of EN (LN) years also has slightly higher (lower) moisture content than the climatological mean. This is consistent with the sign of the rainfall anomalies shown in Fig. 1 although this analysis cannot discern causality (e.g., increased rainfall in JAS of EN years would serve to moisten the atmosphere in its own right). Composites of the JAS anomalous specific humidity field at $850 \mathrm{hPa}$ (not shown) indicate a zonally elongated band of enhanced (reduced) humidity from the Indochina Peninsula eastward to the WNP during EN (LN) events, straddled by anomalies of opposite sign to the north and south (including most of Indonesia). By OND the second term (not shown) indicates a reduction (enhancement) of the climatological moisture flux into the northern and central Philippines during EN (LN), consistent with the development of the anomalous anticyclonic (cyclonic) circulation at $850 \mathrm{hPa}$ but still of relatively small importance in comparison with the first term. The last term in Eq (1), the anomalous eddy moisture flux (not shown) does not significantly contribute to the anomalous flux during any period between JAS and OND, being considerably smaller than even the second term. Overall, this analysis indicates the primary role of the anomalous low-level wind field in determining moisture flux changes across the (a) JAS EI Niño $q_{c} \boldsymbol{V}_{a}$

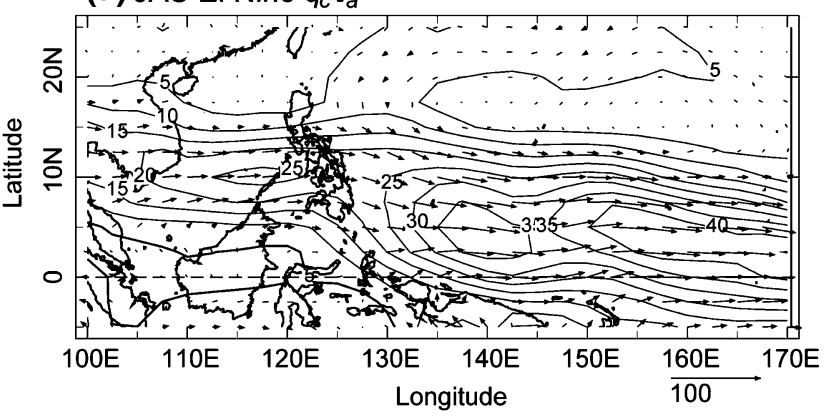

(b)OND EI Niño $q_{c} \boldsymbol{V}_{a}$

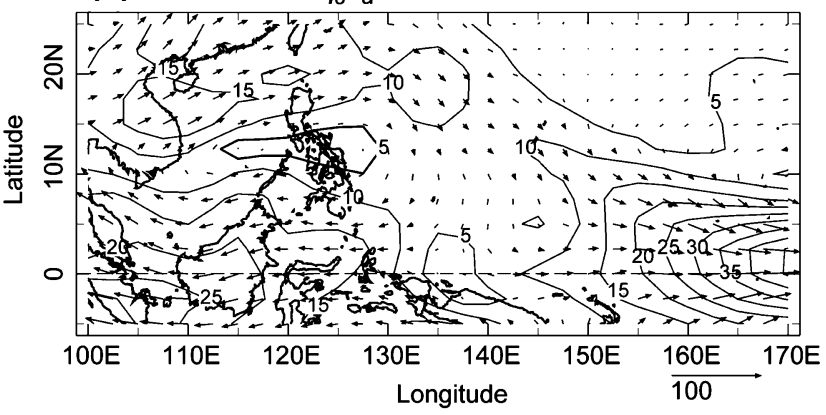

(c) JAS La Niña $q_{c} \boldsymbol{V}_{a}$

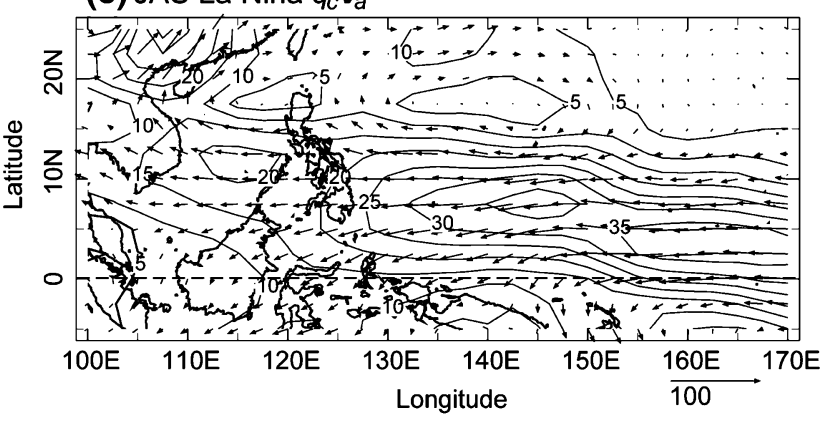

(d) OND La Niña $q_{c} V_{a}$

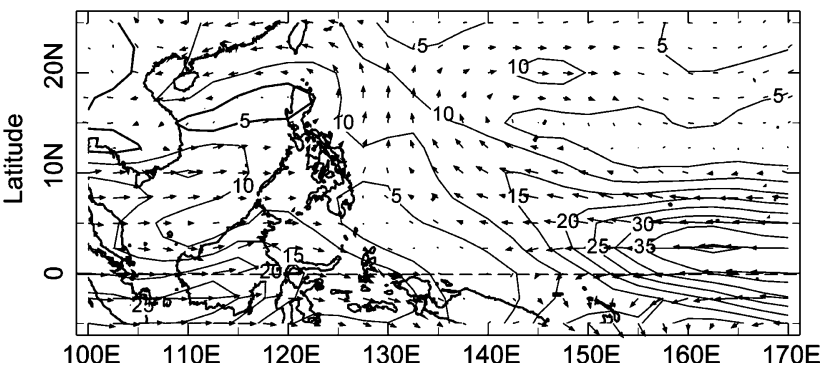

Fig. 6 Horizontal moisture flux composite anomalies at $850 \mathrm{hPa}$ (vectors) and their magnitude (contours; units $\mathrm{kg} \mathrm{kg}^{-1} \mathrm{~ms}^{-1} \times 10^{3}$ ) associated with the product of the anomalous wind and climatological specific humidity during JAS and OND of El Niño (a) and (b), and La Niña events (c) and (d)

Philippines during ENSO events. Similar to the wind field anomalies in Fig. 3, the largest anomalies in the $850 \mathrm{hPa}$ moisture flux are generally located over the central Philippines. 
Fig. 7 As in Fig. 6 but for the product of the anomalous specific humidity and climatological wind in JAS of a El Niño, and b La Niña years (a) JAS EI Niño $q_{a} V_{c}$

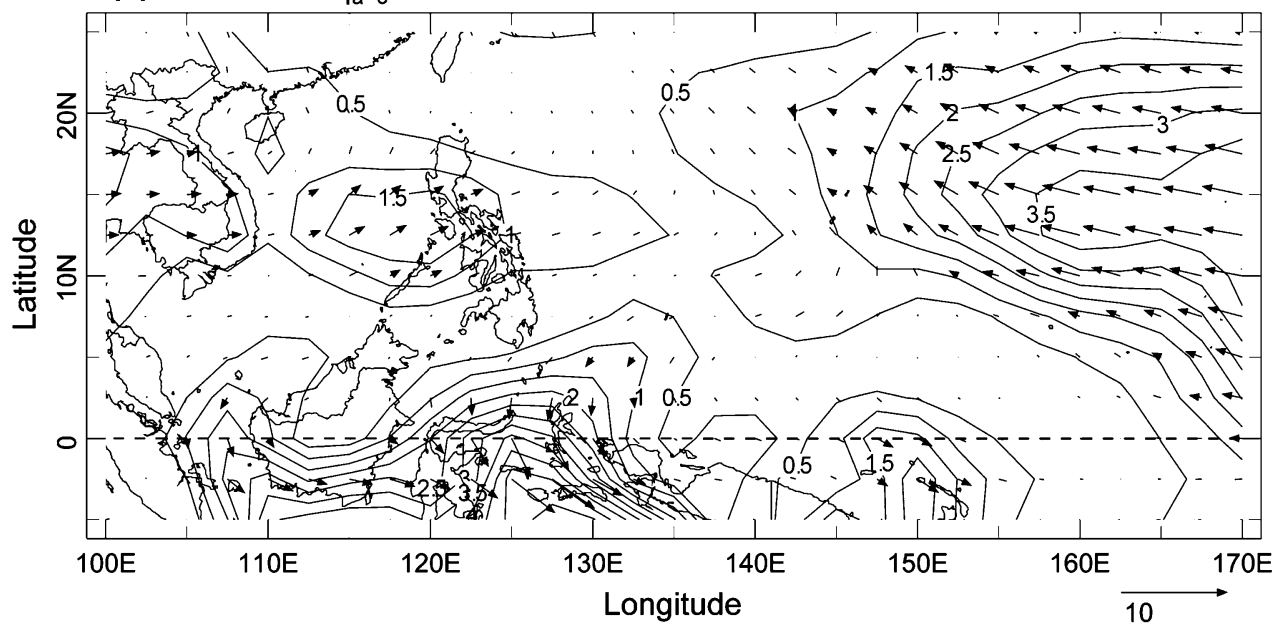

(b) JAS La Niña $q_{a} V_{c}$

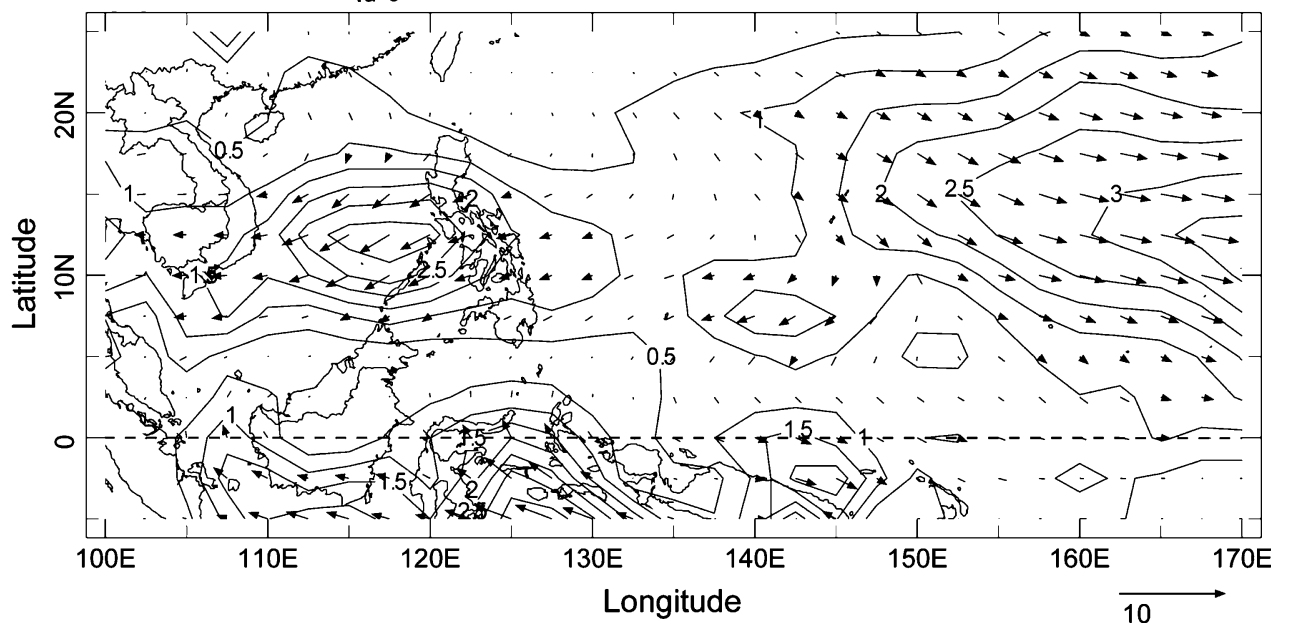

\section{TCs affecting the Philippines}

TCs can contribute significantly to monthly and seasonal rainfall totals in the Philippines. In this section only those TCs whose center either crossed, or came within $100 \mathrm{~km}$ of the coast of the Philippines were considered. The seasonal distribution of TCs whose center either crossed or came within $100 \mathrm{~km}$ of the coastline of the Philippines indicates (Fig. 8) they can occur in all calendar months but are most frequent between July and November. The monthly distribution of TCs is also seen to be bimodal with peaks in July and October, which is related to the seasonal, meridional translation of the monsoon trough (Lander 1996). Virtually all of the TCs considered here had genesis locations west of $160 \mathrm{E}$ which is the eastern boundary of our analysis domain.

The first step in the analysis here was to compare the composite TC track densities during JAS and OND for EN versus LN events. JAS track density differences for the composite EN minus LN are shown in Fig. 9a. Positive differences are seen to extend from the northern SCS southeastward across the north-central Philippines to the WNP. For OND (Fig. 9b) the track density differences indicate a reduced occurrence of TCs over the central Philippines in EN versus LN, consistent with previous studies by Saunders et al. (2000) and Elsner and Liu (2003). The spatial patterns in Fig. 9a and b also show some notable differences, besides having generally opposite sign. The largest differences in track density in OND are located south of those in JAS, related to the southward migration of the monsoon trough with season. Also seen in OND is evidence for re-curving TC trajectories east of the Philippines in EN versus LN years, consistent with previous work (Camargo et al. 2007b). Note, however, that track density is affected by both the total number of TCs, as well as track characteristics and storm lifetime. For instance, a near-stationary TC will contribute to the track density in the grid box(es) associated with the storm's location. A comparison of the number of days in which TCs directly affected the Philippines (center crossing, or coming within 
Mean number of TCs per month Philippines 1950-2004

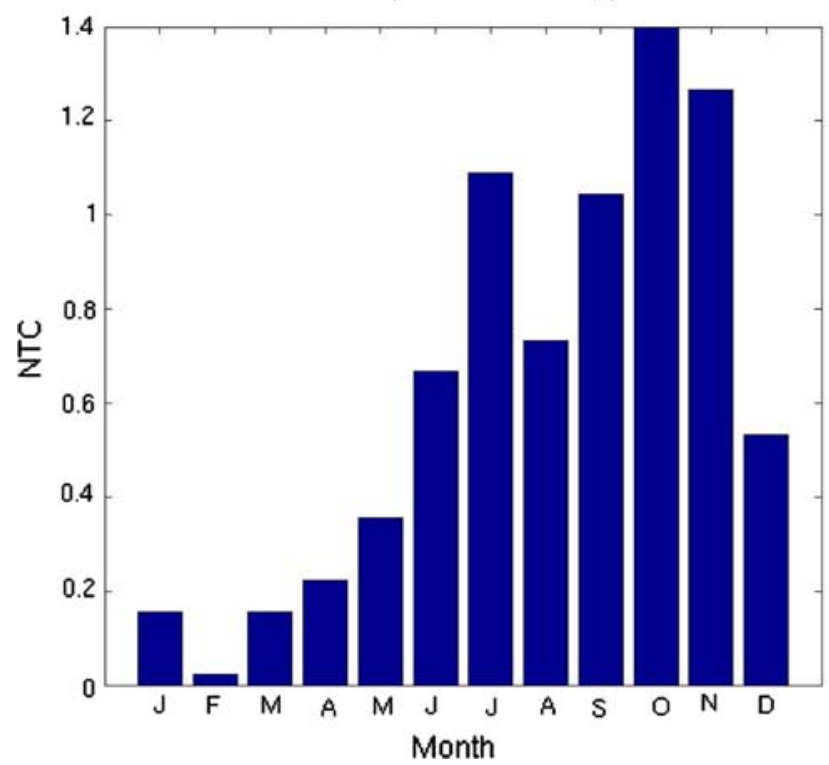

Fig. 8 Climatological distribution of the average number of TCs affecting the Philippines (1950-2004)
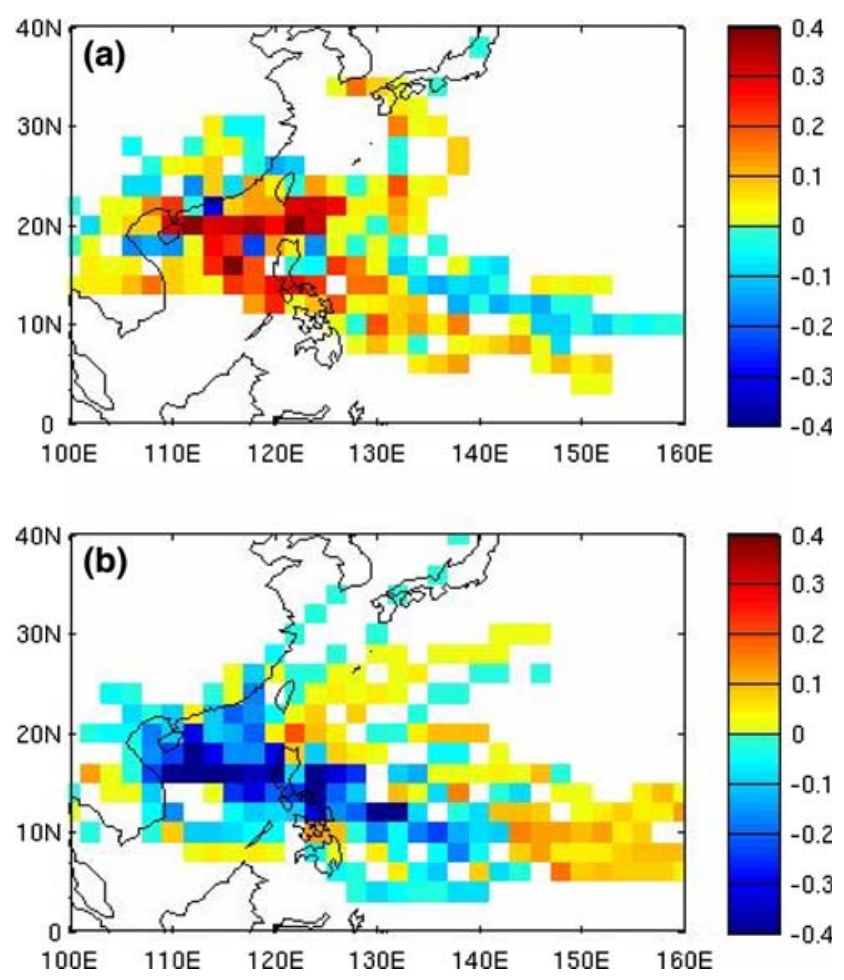

Fig. 9 Composite TC track density differences (El Niño-La Niña) for a JAS and $\mathbf{b}$ OND

$100 \mathrm{~km}$ of the coast), however, indicates a tendency for more (fewer) TCs in JAS during EN (LN) years before this tendency reverses by OND (Fig. 10).

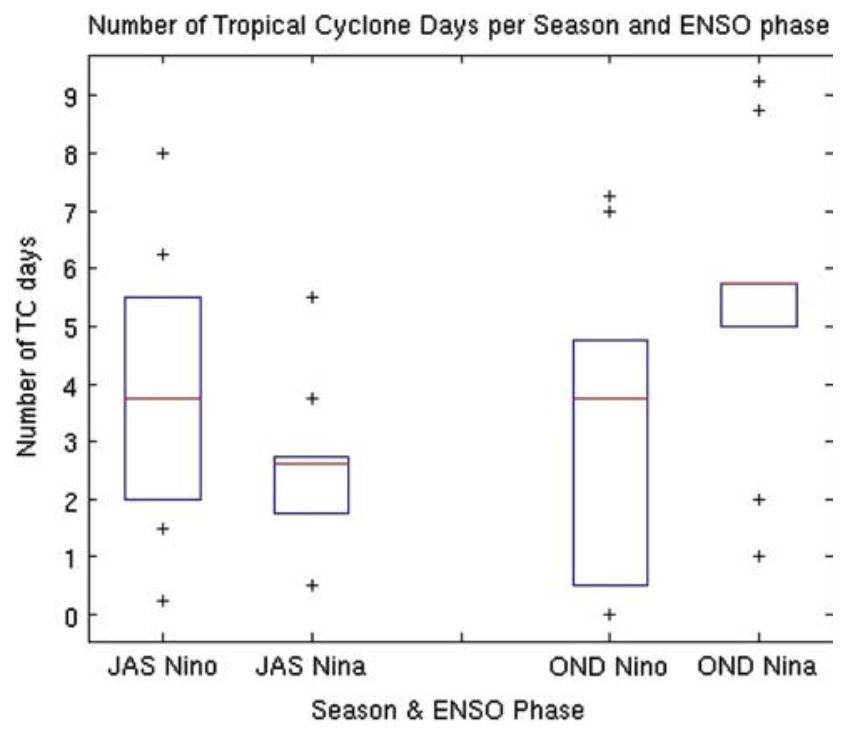

Fig. 10 Number of TC days when the center of a TC was either over the Philippines or within $100 \mathrm{~km}$ of the coast by season and ENSO phase. The boxes are formed by the 25 th and 75 th percentiles with the median shown by the horizontal red lines. Crosses indicate values beyond the outer quartiles

In order to evaluate environmental factors that affect the genesis of Philippines TCs, we use a genesis potential (GP) index (Emanuel and Nolan 2004; Camargo et al. 2007a):

$\mathrm{GP}=\left|10^{5} \eta\right|\left(\frac{\mathrm{RH}}{50}\right)^{3}\left(\frac{V_{\text {pot }}}{70}\right)^{3}\left(1+0.1 V_{\text {shear }}\right)^{-2}$,

where $\eta$ is the absolute vorticity at $850 \mathrm{hPa}$ in $\mathrm{s}^{-1}, \mathrm{RH}$ the relative humidity at $600 \mathrm{hPa}$ in percent, $V_{\text {pot }}$ the potential intensity in $\mathrm{ms}^{-1}$, and $V_{\text {shear }}$ the vertical wind shear, computed as the magnitude of the difference in vector wind between 200 and $850 \mathrm{hPa}$ in $\mathrm{ms}^{-1}$. Evaluation of the potential intensity term requires SST, sea level pressure and vertical profiles of atmospheric temperature and humidity. Technical details on the potential intensity calculation can be found in Emanuel (1995) and Bister and Emanuel (1998, 2002a, b). The potential intensity depends on the air-sea thermodynamic disequilibrium and the difference between SST and the atmospheric temperature at the level of neutral buoyancy for an adiabatically lifted boundary layer parcel. Note that the second and third terms in Eq. (3) are weighted more heavily, with the negative exponent on the last term indicating the inhibitive effect of vertical wind shear on TC development. Detailed discussion on the development of GP index, its climatology and ability to reproduce ENSO impacts on global TC activity are given in Camargo et al. (2007a) where a comparison of the climatological distribution of GP and TC occurrence in the WNP indicates a close correspondence (their Fig. 4c).

Composites of the GP were computed for EN and LN events in both JAS and OND. Differences in GP for JAS 
and OND between ENSO phases (Fig. 11) are generally consistent with the track density differences shown in Fig. 9. To examine which environmental conditions had the largest contribution to these GP differences, each of the four terms in Eq. (3) was evaluated separately based on its composite EN or LN value while setting the other three terms to their climatological mean. The largest contribution to the GP composite anomalies for EN and LN was identified as the relative humidity at mid-levels. The absolute vorticity term had the same sign but was smaller in magnitude (also note the larger weight on the RH term in Eq. 3). The differences in GP using the composite EN or LN RH term while holding the other terms to their climatological values are shown in Fig. 10 for JAS and OND. Consistent with the moisture flux analysis at $850 \mathrm{hPa}$ (cf. Fig. 6), increased (decreased) mid-level moisture during JAS of EN (LN) years leads to higher (lower) GP.

The confluence zone where monsoonal westerlies meet low-latitude easterlies over the WNP is a region conducive to TC formation (e.g. Briegel and Frank 1997). Ritchie and Holland (1999) associated $70 \%$ of all TC genesis with either the monsoon shear line or this confluence region. Changes in the location and strength of the monsoon trough therefore, lead to different genesis location and track types, some of which are characteristic of EN or LN years (Camargo et al. 2007b). Therefore, the changes in vorticity and moisture flux in the monsoon trough region identified
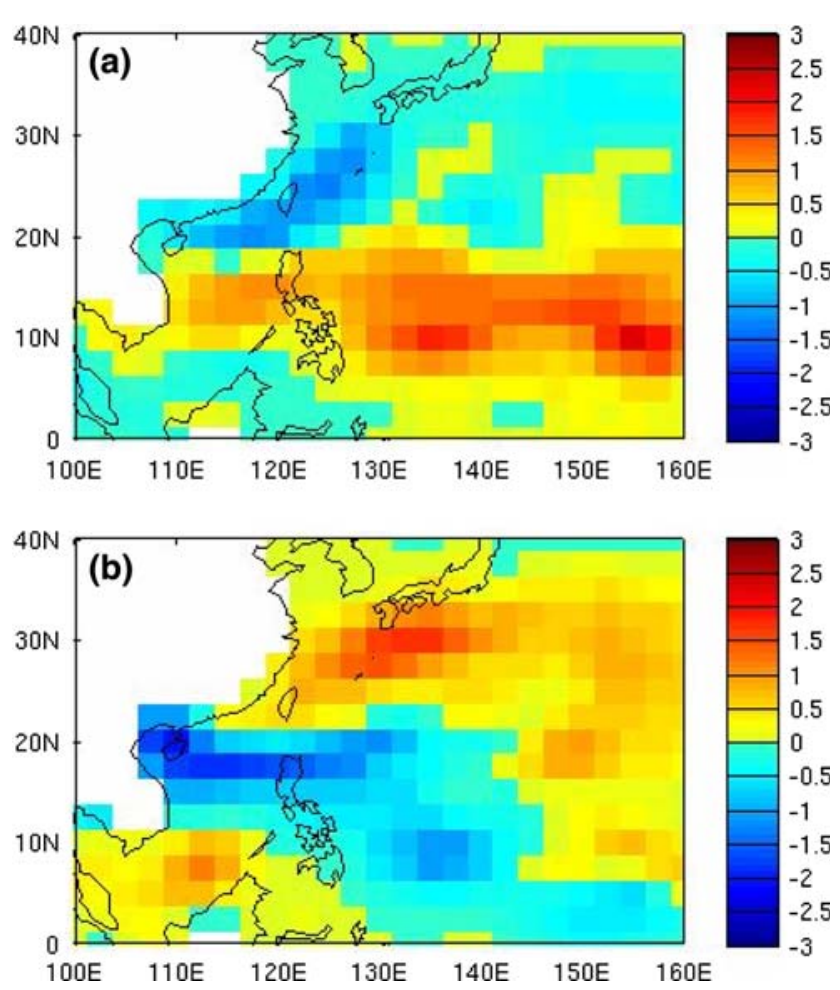

Fig. 11 Differences in the genesis potential for JAS minus OND in a El Niño b La Niña in Figs. 6 and 7 are consistent with the observed changes in Philippines TC activity. For instance, in OND of EN years, the monsoon trough extends further in the central region of the Pacific bringing more moisture to the region (as identified by the GP) and leading to TC formation at a more eastward location, and re-curving tracks east of the Philippines.

The identified tendency for higher (lower) TC activity during JAS of EN (LN) events is qualitatively consistent with the observed increase (decrease) in seasonal rainfall in the north-central Philippines during JAS. To gain a more quantitative sense of the contribution of TCs to seasonal rainfall in the central Philippines pentad (5-day) CMAP data was used in conjunction with the best track data for TCs for the period 1979-2004. Linear interpolation was used to first convert the pentad rainfall to daily values and the grid points closest to the land area in the central Philippines (inner boxed region in Fig. 12a) identified. As an admittedly rough estimate, daily rainfall (averaged over these grid points) was attributed to a TC during those days when the center of the TC was located within the outer box in Fig. 12a. By this method, the climatological contribution of TCs to seasonal rainfall was assessed, along with the contribution of TCs to seasonal rainfall during the six EN (1982, 1986, 1991, 1994, 1997, 2002) and 3 LN (1988, 1998, 1999) events in the analysis period. The results,
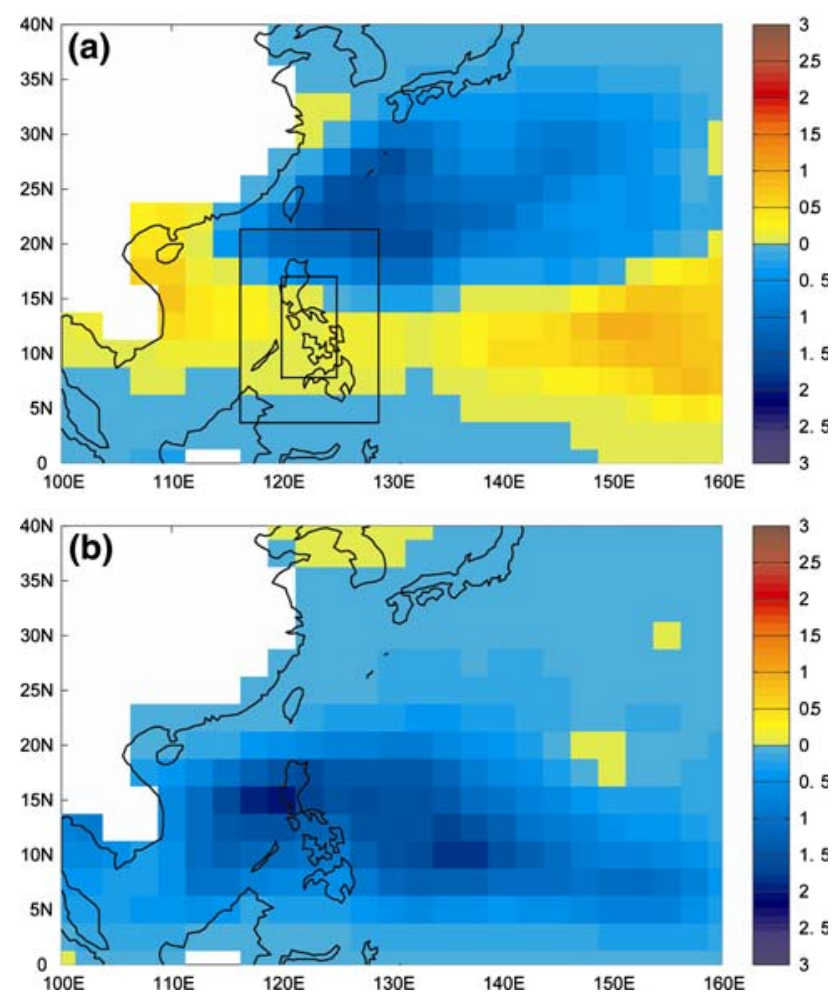

Fig. 12 Differences in genesis potential (El Niño minus La Niña) varying only the RH term for a JAS and b OND 
summarized in Table 1, are consistent with changes in TC track density (Fig. 9) during the seasonal reversal of the ENSO rainfall signal between JAS and OND. The contribution of TCs to seasonal rainfall during EN (LN) is seen to be above (below) the long term mean during JAS when overall rainfall is also above (below) average. The relative contribution of TCs to seasonal rainfall then reverses sign in OND, again consistent with the seasonal reversal of the ENSO signal.

\section{The anomalous large scale circulation, prolonged ENSO events}

Our analysis placed the regional atmospheric circulation features in a broader spatial scale context of ENSO evolution. Two aspects of this evolution are of particular interest here: (a) the seasonal evolution of large scale ENSO features between boreal summer and fall, and (b) the seasonal response to ENSO during prolonged EN and LN episodes.

\subsection{Composite seasonal evolution}

Here seasonal composites of the anomalous $850 \mathrm{hPa}$ streamfunction and $500 \mathrm{hPa}$ pressure vertical velocity fields were constructed. Reanalysis vertical velocity anomalies were used as a proxy for anomalous precipitation, as the CMAP precipitation data only extends back to 1979. It is recognized that the climatological precipitation (and therefore diabatic heating and vertical velocity fields) in the reanalysis have known biases (e.g., Annamalai et al. 1999; Trenberth and Guillemot 1998). However, the focus here is on large-scale anomaly patterns, which at least partially addresses the amplitude issue. Two base periods were nonetheless used in computing anomalies, as was done in the moisture flux computations. For reference, JAS composite precipitation anomalies for the six EN and four $\mathrm{LN}^{4}$ events occurring between 1979 and 2002 were constructed using the CMAP data (Fig. 13).

Figure 14a shows during JAS of EN years a zonally elongated region of statistically significant, anomalous ascent (enhanced rainfall) centered at approximately $10^{\circ} \mathrm{N}$ and extending westward across the central Philippines and WNP monsoon trough region. Broad scale, anomalous subsidence is observed over Indonesia. Compared with the composite CMAP anomalies (Fig. 13a) the reanalysis is underestimating the positive anomalies along the equator in JAS near $165^{\circ} \mathrm{E}$. However, for both the CMAP and

\footnotetext{
${ }^{4}$ Owing to the small sample of cases, the weak La Niña of 19951996 , not identified as an event by the general methodology of the study, was included in the CMAP composite shown in Fig. 13b.
}

Table 1 Contribution of TCs to seasonal rainfall in the central Philippines

\begin{tabular}{llllll}
\hline & \multicolumn{3}{l}{ JAS } & & \multicolumn{2}{l}{ OND } \\
\cline { 2 - 3 } \cline { 5 - 6 } & $\begin{array}{l}\text { Total } \\
(\mathrm{mm})\end{array}$ & $\begin{array}{l}\text { Dif. from mean } \\
(\%)\end{array}$ & $\begin{array}{l}\text { Total } \\
(\mathrm{mm})\end{array}$ & $\begin{array}{l}\text { Dif. from mean } \\
(\%)\end{array}$ \\
\hline Mean & 53.7 & $(20.4)$ & 53.8 & $(27.0)$ \\
El Niño & 69.7 & +29.8 & 38.8 & -27.9 \\
La Niña & 47.9 & -10.8 & 86.0 & +59.8 \\
\hline
\end{tabular}

reanalysis data it is clear that: (a) in addition to the prototypical eastward shift of equatorial convection away from Indonesia during JAS of EN years, there are also substantial off-equatorial rainfall (and therefore, diabatic heating) anomalies; and (b) the largest precipitation anomalies in JAS over the tropical Pacific are located west of the International Date Line. The asymmetric pattern in the anomalous streamfunction field about the equator and west of the Date Line in Fig. 14a is in fact reminiscent of a Gill-type (Gill 1980) response to an off-equatorial, northern hemisphere heat source, with westerly wind anomalies centered north of the equator and a westward shift of the center of the $\mathrm{NH}$ cyclone relative to its southern hemisphere counterpart. Hendon (2003) has suggested that similar behavior, but of opposite sign, occurs farther west in response to negative rainfall anomalies (anomalous cooling) centered south of the equator over the eastern Indian Ocean during EN onset in boreal summer (e.g., see the negative streamfunction anomalies centered near $85 \mathrm{E}$, $10^{\circ} \mathrm{S}$ in Fig. 15a). To the extent that linearity applies, the large-scale composite anomaly pattern in Fig. 12a would thus represent the juxtaposition of the responses from these anomalous heating and cooling centers. The asymmetric response during the onset of ENSO events is currently being explored in more detail.

The subsequent evolution during EN (Fig. 14b-d) shows the anomalous cyclonic circulation located east of the Philippines in JAS moving southeastward, as well as the anomalous westerlies over the WNP. The upward vertical velocity (enhanced rainfall) anomalies over the WNP weaken, while becoming concentrated in the equatorial Pacific east of the date line. An anomalous anticyclonic circulation develops over the SCS and the Philippines. By OND (Fig. 14d) the vertical velocity anomalies in the tropical Pacific are generally centered on the equator east of the date line, straddled by rather symmetric, anomalous low-level cyclones. A similar, anticyclonic couplet is centered roughly on the equator over the eastern Indian Ocean.

The evolution of the composite LN events (Fig. 15) is generally opposite that of EN, with the exception of the location of the anomalous anti-cyclonic circulation east of 
Fig. 13 Composite CMAP rainfall anomalies (units mm day ${ }^{-1}$ ) during JAS for a six El Niño, and $\mathbf{b}$ four La Niña events

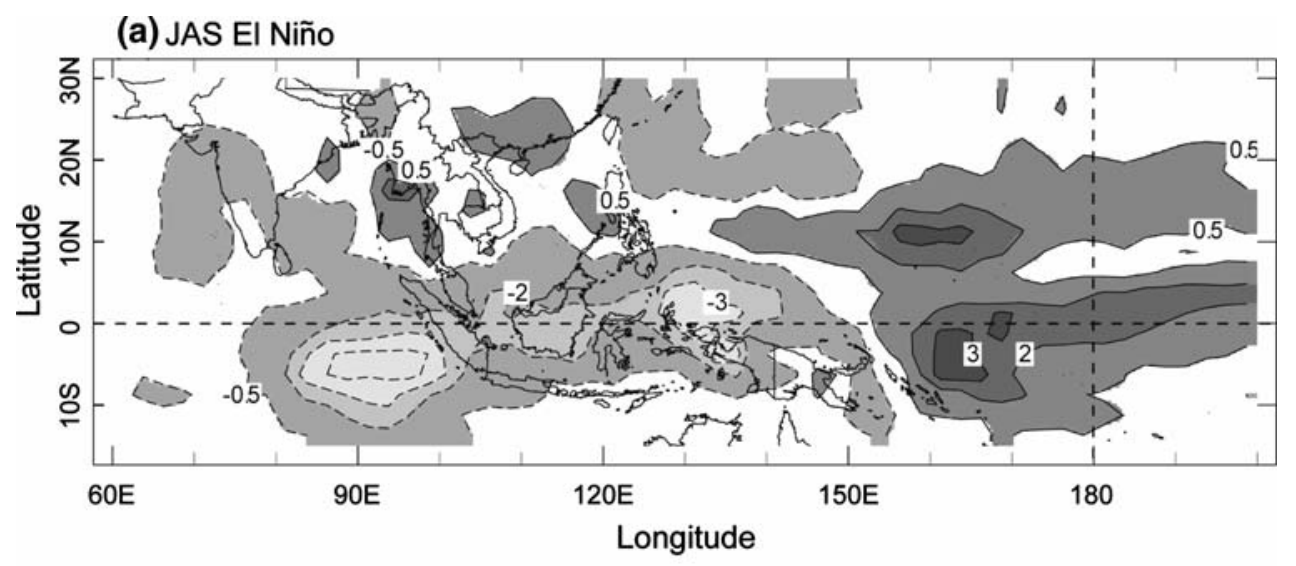

(b) JAS La Niña

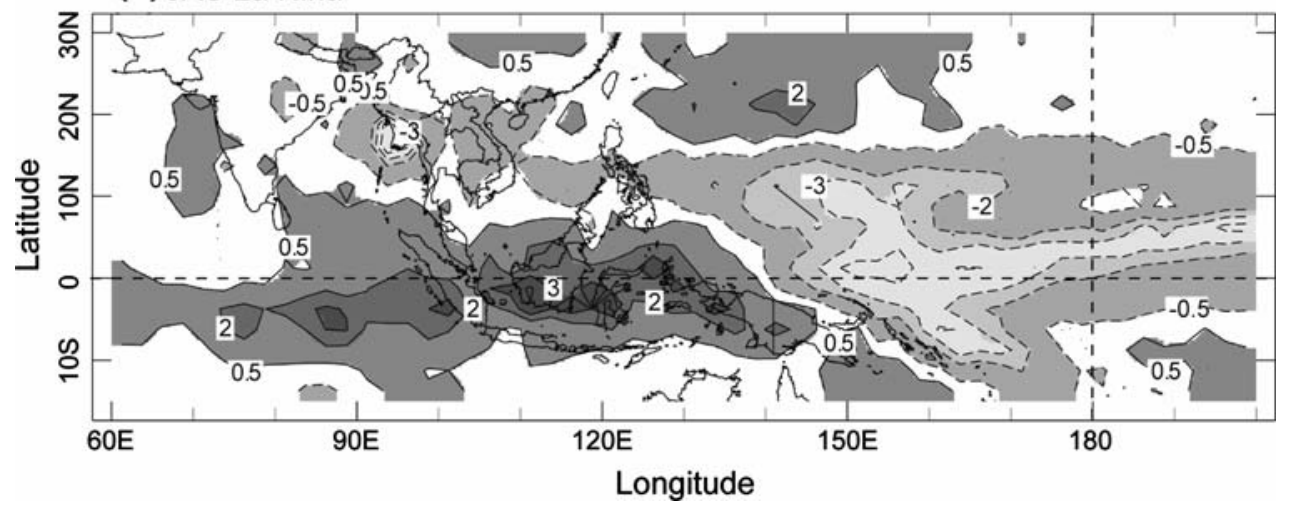

the Philippines being slightly west of its EN counterpart. This is consistent with the location of the downward vertical velocity anomalies (decrease in rainfall) extending approximately $20^{\circ}$ of longitude west of the date line in OND. Similar to the EN composite, in JAS of LN the anomalous streamfunction field exhibits an asymmetric pattern about the equator west of the date line, before a much more symmetric pattern is established by OND.

\subsection{Prolonged ENSO events}

An empirical orthogonal function (EOF) analysis was performed on standardized $850 \mathrm{hPa}$ streamfunction anomalies over the WNP for all JAS and OND seasons 19502002. The leading EOF loading patterns for JAS and OND, accounting for 60.9 and $33.9 \%$ of the total variance, respectively are shown in Fig. 16, along with their associated principal component time series. Also plotted in Fig. 16 are time series of seasonal SST anomalies averaged over the Niño3.4 region for both seasons. In JAS (Fig. 16 a), the correlation of the time series of the first EOF with Niño3.4 SST is 0.86. During the three consecutive JAS seasons of the period 1973-1975, the principal component time series remained negative, indicating an anomalous anticyclonic circulation located east of the Philippines. Similar behavior is seen in the two consecutive JAS seasons of the LN in 1998 and 1999. Conversely, the PC time series remained positive during the prolonged EN events of 1986-1987 and 1991-1992 indicating an anomalous cyclone.

The correlation of the time series of the first EOF in OND with Niño3.4 SST is $r=0.84$, consistent with the similarity between the first EOF and the OND streamfunction patterns (Fig. 3). The time series for OND also has values of the same sign in consecutive years of the two prolonged LN and EN events. Therefore, the evolution of the anomalous low-level atmospheric circulation during prolonged ENSO events is essentially a repetition of the typical life cycle described earlier. In other words, the atmospheric response to anomalous SSTs associated with prolonged ENSO episodes is highly dependent on the seasonally varying climatological background state.

This behavior is also shown in Fig. 17 where time series of the anomalous $850 \mathrm{hPa}$ relative vorticity averaged over the north-central Philippines (boxed region in Fig. 4a) are plotted for the two prolonged LN events. A 3-month running average was applied to the time series. Figure 17 indicates that both prolonged LN events were immediately preceded by EN events (in 1972 and 1997) with positive vorticity anomalies peaking in the boreal summer at the start of both time series. As these respective EN events matured during the boreal fall, negative vorticity anomalies 
(a) JAS EI Niño

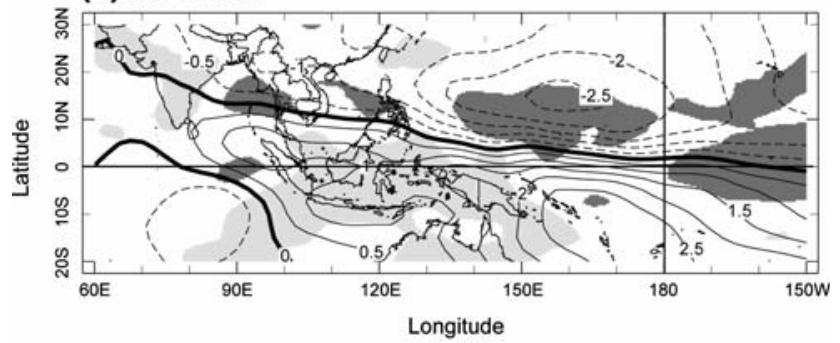

(b) ASO EI Niño

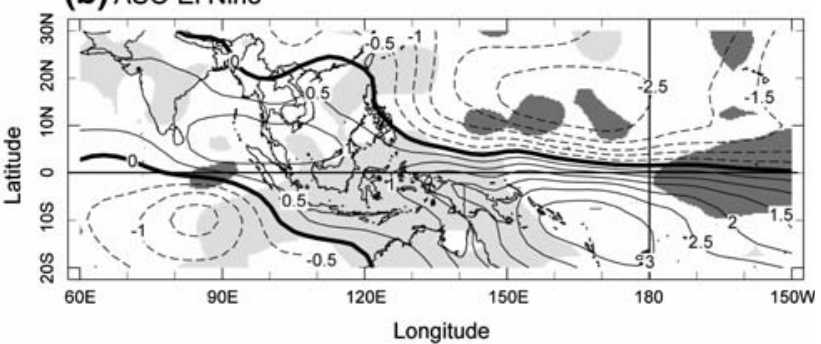

(c) SON EI Niño

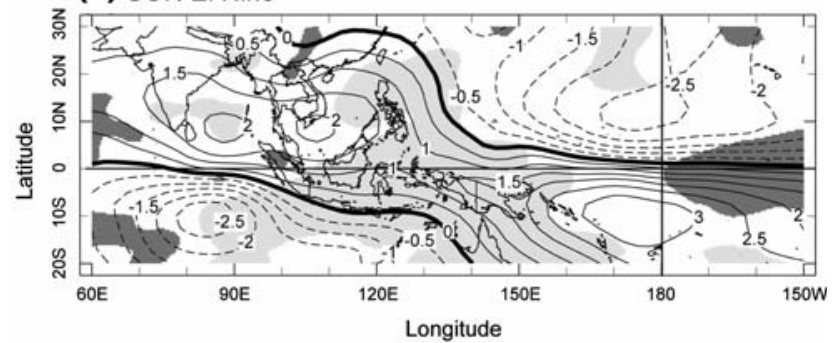

(d) OND EI Niño

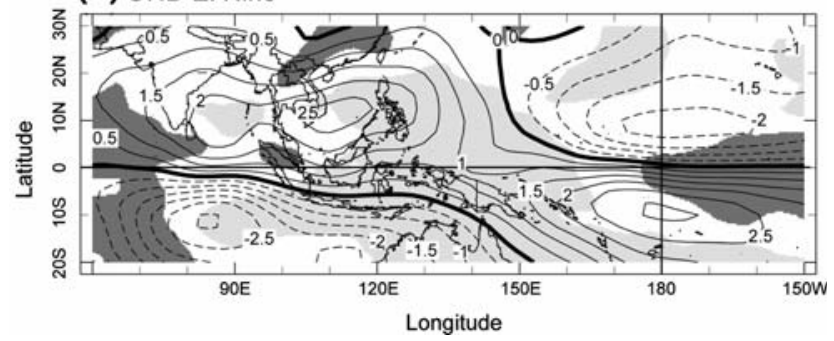

Fig. 14 Seasonal evolution of composite $850 \mathrm{hPa}$ streamfunction anomalies (contours; units $\mathrm{m}^{2} \mathrm{~s}^{-1} \times 10^{6}$ ) and regions where the composite vertical pressure velocity anomalies at $500 \mathrm{hPa}$ show statistically significant occurrence of downward (light shading) and upward (dark shading) motion at the $95 \%$ confidence level

developed, consistent with the unusually dry conditions in the Philippines in both years. Both of these EN events subsequently weakened, with transitions to LN occurring during boreal spring and early summer (of 1973 and 1998) when negative vorticity anomalies (associated with decreased rainfall) developed. These negative anomalies then weakened during the boreal fall and positive anomalies (and increased rainfall) again emerged, completing the seasonal reversal. This cycle repeats in 1974-1975.

Close scrutiny of Fig. 2 indicates that in JAS of the 1999 LN rainfall across the north-central Philippines was in fact (a) JAS La Niña

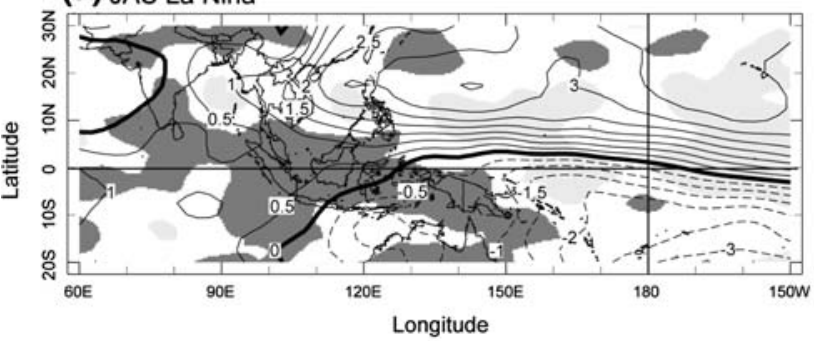

(b) ASO La Niña

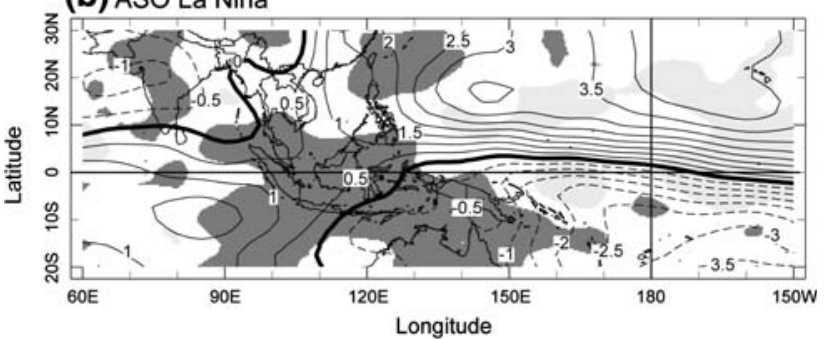

(c) SON La Niña

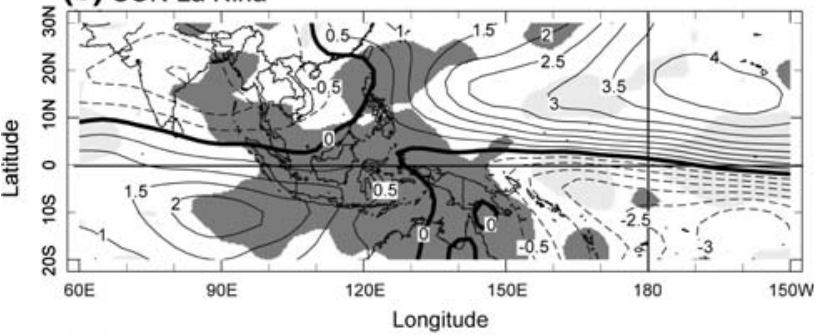

(d) OND La Niña

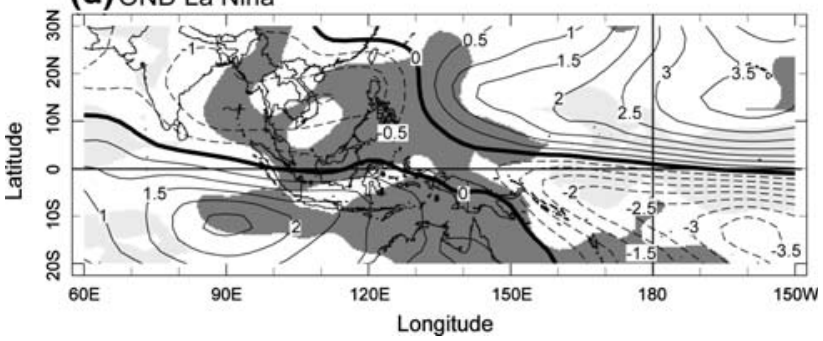

Fig. 15 As in Fig. 14 but for the composite La Niña

above average. This was primarily the result of very heavy rainfall in western Luzon (upper-left of box in Fig. 1a). Farther to the south and east, several locations had much below average rainfall during the JAS season in 1999 .

\section{Summary and conclusions}

During JAS of EN (LN) years, seasonal rainfall shows a statistically significant occurrence of being above (below) the long-term average across the north-central Philippines, before rainfall anomalies of opposite sign develop across the country during boreal fall. The analyses shown indicate the anomalous low-level wind response across the WNP in JAS of EN (LN) years includes an off-equatorial, zonally 
(a) JAS
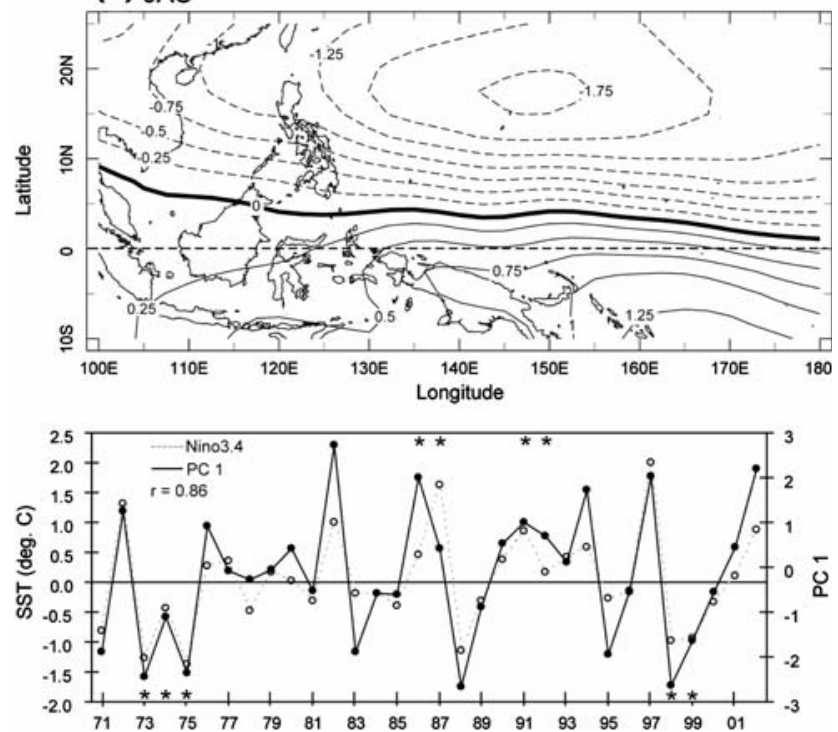

(b) OND
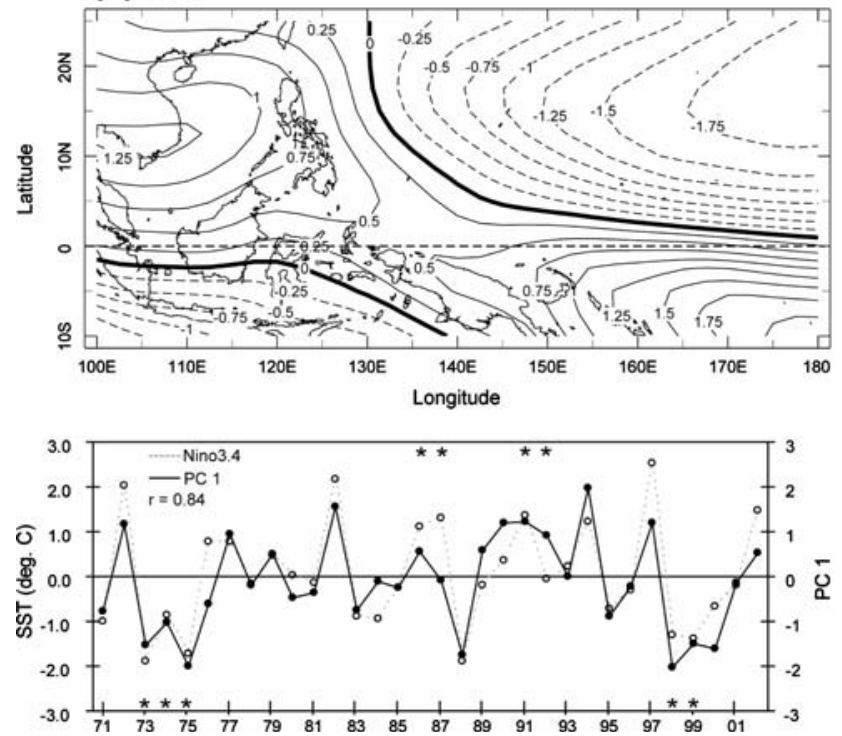

Fig. 16 EOF loading patterns (contours) and associated principal component time series (1971-2002) obtained from standardized values of $850 \mathrm{hPa}$ streamfunction anomalies for a JAS and, b OND seasons. Time series of a Niño3.4 SST anomaly index (units ${ }^{\circ} \mathrm{C}$ ) are also indicated for both seasons

elongated band of enhanced (reduced) westerly flow. This anomalous flow acts to increase (decrease) the moisture flux into the north-central Philippines during JAS of EN (LN) events while its horizontal shear is associated with a strengthened (weakened) WNP monsoon trough, consistent with the sign of the associated rainfall anomalies. Collectively, these results provide an explanation why in JAS the ENSO rainfall signal is limited to such a narrow geographic area of the Philippines. The country's geographic location (centered at roughly $12^{\circ} \mathrm{N}$ and $122^{\circ} \mathrm{E}$ ) is such that it is directly influenced by this relatively narrow band of off-equatorial low-level zonal wind anomalies which enhance (reduce) the summer monsoon flow as EL (LN) events develop.

This band of anomalous low-level westerly (easterly) winds is in turn associated with an anomalous cyclonic (anticyclonic) circulation, which typically develops over the WNP east of the Philippines during JAS of EN (LN) events. Modeling studies (Lau et al. 2004; Wu et al. 2003, among others) indicate that this anomalous circulation feature is largely a response to remote forcing by anomalous convection over the central tropical Pacific. In addition to the anomalous heating associated with the prototypical eastward shift of equatorial convection away from Indonesia during EN development, the enhanced convection north of the equator in the WNP also serves as an anomalous heat source. The asymmetry of the lowlevel atmospheric circulation across the WNP in JAS is in fact similar to that of a linear model response to an offequatorial heat source in JAS (in both EN and LN). Unlike Indonesia where local SST anomalies in boreal summer act to reinforce remote forcing from the central Pacific (Hendon 2003), in the north-central Philippines the JAS rainfall response to EN and LN appears to be primarily a result of the remote forcing, as local SST anomalies are typically of opposite sign as the rainfall anomalies.

The subsequent temporal evolution of the low-level circulation appears to be closely tied to an eastward translation of anomalous convection in the tropical Pacific as EN and LN events mature. An anomalous anticyclonic (cyclonic) circulation develops rapidly in the vicinity of the Philippines during boreal fall of EN (LN) years, associated with the tendency for reduced (enhanced) rainfall in OND. The anomalous streamfunction pattern at $850 \mathrm{hPa}$ across the Pacific becomes much more symmetric about the equator by OND. A similar evolution of the atmospheric circulation was shown for multi-year LN events, when seasonal reversals in the rainfall signal in the north-central Philippines were also observed. These results indicate the importance of the seasonally varying background climate in determining the atmospheric response to the forcing from the anomalous SSTs associated with these prolonged LN events.

Qualitatively consistent with the seasonal rainfall signal reversal, TCs affecting the Philippines were found to occur more (less) frequently in the north-central Philippines during JAS of EN (LN) events before the opposite tendency develops by boreal fall. The GP index analysis shows that the largest environmental factor affecting TC genesis is the RH in the mid-troposphere, which increases (decreases) during JAS of EN (LN) years and is consistent with the analysis of anomalous moisture flux patterns provided in Sect. 3. 
Fig. 17 Time series of the anomalous $850 \mathrm{hPa}$ relative vorticity (solid lines; units $\mathrm{s}^{-1} \times 10^{6}$ ) averaged over the boxed region centered on the north-central Philippines shown in Fig. 4a along with the annual cycle of CMAP precipitation averaged over the same region (dashed lines; units mm day ${ }^{-1}$ ) for a April 1972-Dec 1975 and b April 1997-December 2000.

The time series were smoothed using a 3-month running average (a) $1972-75$

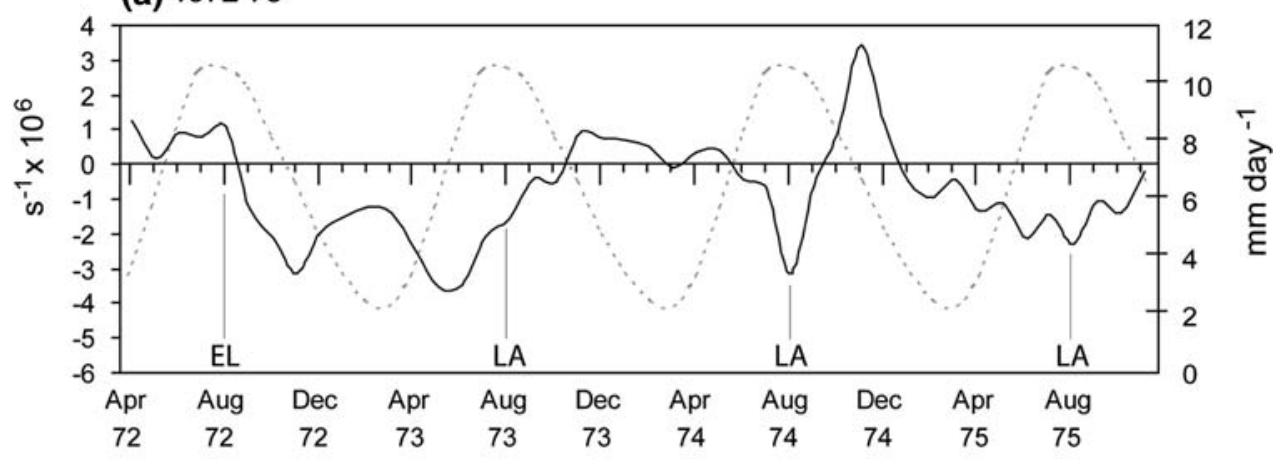

(b) $1997-00$

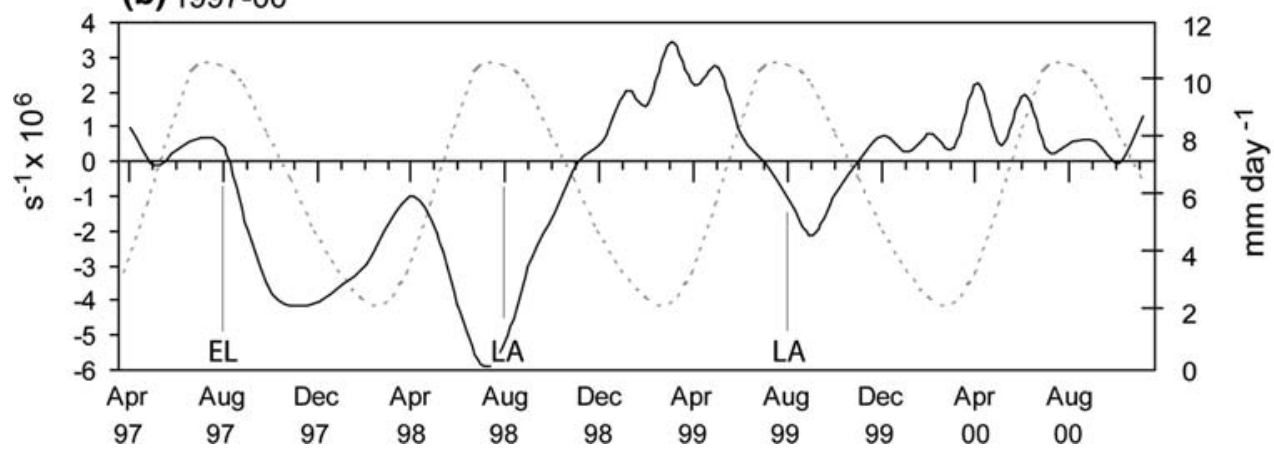

Acknowledgments This study is an outgrowth of a collaborative research effort between the Philippine Atmospheric, Geophysical and Astronomical Services Administration (PAGASA) and the International Research Institute for Climate and Society (IRI). The authors wish to thank Dr. Flaviana Hilario, head of the Climatology and Agrometeorology Branch, Edna L. Juanillo, head of the Climate Monitoring and Prediction Center (CLIMPC), and Anthony Lucero of PAGASA for their assistance during the course of this work. This work is funded in part by a grant from the National Oceanographic and Atmospheric Administration (NOAA), NA050AR4311004, and by the US Agency for International Development's Office of Foreign Disaster Assistance, DFD-A-00-0300005-00. The views expressed herein are those of the authors and do not necessarily reflect those of NOAA or any of its sub-agencies.

\section{References}

Annamalai H, Slingo JM, Sperber KR, Hodges K (1999) The mean evolution and variability of the Asian summer monsoon: comparison of ECMWF and NCEP NCAR reanalyses. Mon Weather Rev 127:1157-1186

Barnston AG, Chelliah M, Goldenberg SB (1997) Documentation of a highly ENSO-related SST region in the equatorial Pacific. Atmos Ocean 35:367-383

Bister M, Emanuel KA (1998) Dissipative heating and hurricane intensity. Meteor Atmos Phys 52:233-240

Bister M, Emanuel KA (2002a) Low frequency variability of tropical cyclone potential intensity. 1. Interannual to interdecadal variability. J Geophys Res 107:4801, doi:10.1029/2001JD000776

Bister M, Emanuel KA (2002b) Low frequency variability of tropical cyclone potential intensity.2. Climatology for 1982-1995. J Geophys Res 107:4621, doi:10.1029/2001JD000780

Briegel LM, Frank WM (1997) Large-scale influences on tropical cyclogenesis in the western North Pacific. Mon Weather Rev 125:1397-1413
Camargo SJ, Sobel AH (2005) Western North Pacific tropical cyclone intensity and ENSO. J Clim 18:2996-3006

Camargo SJ, Emanuel KA, Sobel AH (2007a) Use of a genesis potential index to diagnose ENSO effects on tropical cyclone genesis. J Clim 20:4819-4834

Camargo SJ, Robertson AW, Gaffney SJ, Smyth P, Ghil M (2007b) Cluster analysis of typhoon tracks. Part II: large-scale circulation and ENSO. J Clim 20:3654-3676

Chan JCL (1985) Tropical cyclone activity in the Northwest Pacific in relation to El Niño/Southern Oscillation phenomenon. Mon Weather Rev 113:599-606

Chan JCL (2000) Tropical cyclone activity over the western North Pacific associated with El Niño and La Niña events. J Clim 13:2960-2972

Chang C-P (ed) (2004) East Asian Monsoon. World scientific series on meteorology of East Asia, vol 2. World Scientific, Singapore, 564 pp

Chang C-P, Wang Z, McBride J, Liu C-H (2005) Annual cycle of Southeast Asia-maritime continent rainfall and the asymmetric monsoon transition. J Clim 18:287-301

Chen T-C, Weng S-P, Yamazaki N, Kiehne S (1998) Interannual variation in the tropical cyclone formation over the western North Pacific. Mon Weather Rev 126:1080-1090

Chia HH, Ropelewski CF (2002) The interannual variability in the genesis location of tropical cyclones in the northwest Pacific. J Clim 15:2934-2944

Elsner JB, Liu K-b (2003) Examining the ENSO-typhoon hypothesis. Clim Res 25:43-54

Emanuel KA (1995) Sensitivity of tropical cyclones to surface exchange coefficients and a revised steady-state model incorporating eye dynamics. J Atmos Sci 52:3969-3976

Emanuel KA, Nolan DS (2004) Tropical cyclone activity and global climate. Bull Am Meteorol Soc 85:666-667

Gill AE (1980) Some simple solutions for heat-induced tropical circulation. Q J R Meteorol Soc 106:447-462

Hendon HH (2003) Indonesian rainfall variability: impacts of ENSO and local air-sea interaction. J Clim 16:1775-1790 
Hoerling MP, Kumar A, Zhong M (1997) El Niño, La Niña, and the nonlinearity of their teleconnections. J Clim 10:1769-1786

Juneng L, Tangang FT (2005) Evolution of ENSO-related rainfall anomalies inSoutheast Asia region and its relationship with atmosphere-ocean variations in Indo-Pacific sector. Clim Dyn 25:337-350

Kiladis GN, Diaz HF (1989) Global climatic anomalies associated with extremes in the Southern Oscillation. J Clim 2:1069-1090

Kistler R et al (2001) The NCEP-NCAR reanalysis: monthly means CD-ROM and documentation. Bull Am Meteorol Soc 82: 247-268

Kripalani RH, Kulkarni A (1998) The relationship between some large-scale atmospheric parameters and rainfall over southeast Asia: a comparison with features over India. Theor Appl Clim 59:1-11

Lander MA (1994) An exploratory analysis of the relationship between tropical storm formation in the western North Pacific and ENSO. Mon Weather Rev 122:636-651

Lander MA (1996) Specific tropical cyclone tracks and unusual tropical cyclone motions associated with a reverse-oriented monsoon trough in the western North Pacific. Weather Forecast 11:170-186

Lau N-C, Nath MJ (2000) Impact of ENSO on the variability of the Asian-Australian monsoons as simulated in GCM experiments. J Clim 13:4287-4309

Lau N-C, Nath MJ (2003) Atmosphere-ocean variations in the IndoPacific sector during ENSO episodes. J Clim 16:3-20

Lau N-C, Nath MJ (2006) ENSO modulation of the interannual and intraseasonal variability of the East Asian monsoon-a model study. J Clim 19:4508-4530

Lau N-C, Nath MJ, Wang H (2004) Simulations by a GFDL GCM of ENSO-related variability of the coupled atmosphere-ocean system in the East Asian monsoon region. In: Chang C-P (ed) East Asian Monsoon. World scientific series on meteorology of East Asia, vol 2. World Scientific, Singapore,pp 271-300

Lyon B, Cristi H, Verceles ER, Hilario FD, Abastillas R (2006) Seasonal reversal of the ENSO rainfall signal in the Philippines. Geophys Res Lett 33:L24710, doi:10.1029/2006GL028182

New M, Hulme M, Jones PD (1999) Representing twentieth century space-time climate variability. Part I: development of a 19611990 mean monthly terrestrial climatology. J Clim 12:829-856

New M, Hulme M, Jones PD (2000) Representing twentieth century space-time climate variability. Part II: development of 1901-96 monthly grids of terrestrial surface climate. J Clim 13:22172238
Ritchie ER, Holland GJ (1999) Large-scale patterns associated with tropical cyclogenesis in the western Pacific. Mon Weather Rev 127:2027-2043

Ropelewski CF, Halpert MS (1987) Global and regional scale precipitation patterns associated with the El Niño/Southern Oscillation. Mon Weather Rev 115:1606-1626

Saunders MA, Chandler RE, Merchant CJ, Roberts FP (2000) Atlantic hurricanes and NW Pacific typhoons: ENSO spatial impacts on occurrence and landfall. Geophys Res Lett 27:1147-1150

Smith TM, Reynolds RW (2003) Extended reconstruction of global sea surface temperatures based on COADS data (1854-1997). J Clim 16:1495-1510

Trenberth KE, Guillemont CJ (1998) Evaluation of the atmospheric moisture and hydrological cycle in the NCEP NCAR reanalyses. Clim Dyn 14:213-231

Walker GT, Bliss EW (1932) World Weather V. Mem R Meteorol Soc 4:53-84

Wang B, Chan JCL (2002) How strong ENSO events affect tropical storm activity over the western North Pacific. J Clim 15:16431658

Wang B, Fan Z (1999) Choice of South Asian summer monsoon indices. Bull Am Meteorol Soc 80:629-638

Wang B, Li T (2004) East Asian Monsoon-ENSO interactions. Chap 5. In: Chang C-P (ed) East Asian Monsoon. World scientific series on meteorology of East Asia, vol 2. World Scientific, Singapore, $564 \mathrm{pp}$

Wang B, Zhang Q (2002) Pacific-East Asian teleconnection. Part II: how the Philippines Sea anomalous anticyclone is established during El Niño development. J Clim 15:3252-3265

Wang B, Wu R, Fu X (2000) Pacific-East Asian teleconnection: how does ENSO affect East Asian climate? J Clim 13:1517-1536

Wang B, Wu R, Lau K-M (2001) Interannual variability of the Asian summer monsoon: contrasts between the Indian and the western North Pacific-East Asian monsoons. J Clim 14:4073-4090

Wang B, Wu R, Li T (2003) Atmosphere-Warm Ocean interaction and its impacts on Asian-Australian Monsoon Variation. J Cim 16:1195-1211

Wu R, Hu Z-Z, Kirtman BP (2003) Evolution of ENSO-related rainfall anomalies in East Asia. J Clim 16:3742-3758

Xie P, Arkin PA (1996) Analysis of global monthly precipitation using gauge observations, satellite estimates, and numerical model predictions. J Clim 9:840-858

Zhang R, Sumi A, Kimoto M (1996) Impact of El Nino on the East Asian monsoon: a diagnostic study of the ' $86 / 87$ ' and '91/92'events. J Meteor Soc Japan 74:49-62 